\title{
Lexical or syntactic control of sentence formulation? Structural generalizations from idiom production ${ }^{\text {th }}$
}

\author{
Agnieszka E. Konopka, Kathryn Bock* \\ Beckman Institute for Advanced Science and Technology, University of Illinois at Urbana-Champaign, \\ 405 North Mathews Avenue, Urbana, IL 61801, USA
}

\section{A R T I C L E I N F O}

\section{Article history:}

Available online 21 July 2008

\section{Keywords:}

Language production

Syntax

Structural priming

Idioms

Lexical syntax

\begin{abstract}
A B S T R A C T
To compare abstract structural and lexicalist accounts of syntactic processes in sentence formulation, we examined the effectiveness of nonidiomatic and idiomatic phrasal verbs in inducing structural generalizations. Three experiments made use of a syntactic priming paradigm in which participants recalled sentences they had read in rapid serial visual presentation. Prime and target sentences contained phrasal verbs with particles directly following the verb (pull off a sweatshirt) or following the direct object (pull a sweatshirt off). Idiomatic primes used verbs whose figurative meaning cannot be straightforwardly derived from the literal meaning of the main verb (e.g., pull off a robbery) and are commonly treated as stored lexical units. Particle placement in sentences was primed by both nonidiomatic and idiomatic verbs. Experiment 1 showed that the syntax of idiomatic and nonidiomatic phrasal verbs is amenable to priming, and Experiments 2 and 3 compared the priming patterns created by idiomatic and nonidiomatic primes. Despite differences in idiomaticity and structural flexibility, both types of phrasal verbs induced structural generalizations and differed little in their ability to do so. The findings are interpreted in terms of the role of abstract structural processes in language production.
\end{abstract}

(c) 2008 Elsevier Inc. All rights reserved.

\footnotetext{
is The research and preparation of the manuscript were supported in part by Grants from the National Science Foundation (BCS-0214270) and by research and training Grants from the National Institutes of Health (R01 MH66089; T32 MH1819990). We thank Elizabeth Octigan and Matthew Rambert for their assistance, and Sarah Brown-Schmidt, Gary Dell, Cynthia Fisher, Ray Jackendoff, Ken McRae, and two anonymous reviewers for helpful suggestions and comments on earlier versions of the manuscript.

* Corresponding author. Fax: +1 2172448371.

E-mail address: jkbock@uiuc.edu (K. Bock).
} 


\section{Introduction}

Sentence formulation requires syntactic information. To convey a message, speakers not only recruit lexical items relevant to their communicative intentions, but also formulate a structural scheme to position these words in well-formed sentences. Understanding structural planning thus involves explaining how information about words and syntax is represented and used in language production. Of necessity, most models of production assume the existence of structurally sensitive processes responsible for word-order. Specific views about the interplay between word retrieval and structure-building, however, vary in terms of the relative contributions that words and more abstract syntactic processes make to the formulation process. We sketch two alternative accounts, a strong lexical account and a strong syntactic account, and derive contrasting predictions from them about the workings of lexicalized and abstract phrasal syntax in the sentence formulation process. These predictions are then tested with idioms, which are a familiar type of lexicalized expression, in a structural priming paradigm.

A strong lexical account of lexical-syntactic integration posits that sentence structure is derived from the syntactic specifications of individually activated words, making word retrieval a prerequisite for the construction of structures. Many models of lexical access assume that a two-step word retrieval process is necessary to allow for the retrieval of words' syntactic specifications and then retrieval of specific sound sequences (see Levelt, Roelofs, \& Meyer, 1999, for a review and a model). Before phonological retrieval and overt production can begin, speakers must select lemmas, or syntactic words, from their mental lexicon. This process yields activation of word-specific syntactic features: Nouns may be classified as denoting mass or count entities, verbs may be tagged as transitive or intransitive, and so on. Such information is necessary for building sentence frames with the right configurations.

The need for lexically specific syntactic information in language use is grounded in part in linguistic analyses of lexical constraints on structure (Wasow, 1977). Syntactic structures have to be influenced by lexically specific regularities: For example, the verb bank in The plane banked and the verb bank in John banked his money are presumably different lexical entries with different syntactic privileges. The syntactic processes building these two sentences must be attuned to such differences. Differences among verbs in their structural constraints (their subcategorizations) and their frequencies of occurrence in alternative structural frames (verb bias) can have substantial effects on comprehension, as listeners can be easily garden-pathed or biased towards a particular sentence interpretation by properties of the main verb in a sentence (e.g., Britt, 1994; Garnsey, Pearlmutter, Myers, \& Lotocky, 1997; Snedeker \& Trueswell, 2004). Because such biases are also seen in the preferences of speakers for certain forms during language production, a major question for production theory is how lexical and structural information are coordinated (Bock, 1987).

From a strong lexicalist perspective, if syntax is uniformly projected from the lexicon, then the deployment of syntactic procedures in the course of production becomes directly contingent upon word selection. Claims of this sort are found in the literature on language acquisition (Tomasello, 2000), language comprehension (MacDonald, Pearlmutter, \& Seidenberg, 1994), and language production (Bock \& Levelt, 1994). If this strong lexicalist hypothesis is right, and words play the dominant role in structure selection, then the role of more abstract syntactic processes may be reduced to the binding of lexically specific syntactic information into larger structures following lexical retrieval (Jackendoff, 2002).

Strong syntactic accounts, on the other hand, give abstract structural configurations a leading role in acquisition (Fisher, 2002a, 2002b), comprehension (Frazier, 1987), and production (Bock, 1990). Structures need not be activated by words but can be the result of a mapping from event structure to syntactic relations, conveying relational correspondences between elements in a message. In production, for example, a speaker intending to communicate a message with two arguments must build a sentence frame capable of expressing two arguments; a speaker intending to communicate a message with three arguments needs a sentence frame that accommodates three arguments. According to this view, speakers must have syntactic mechanisms that can generate abstract sentence representations, or frames, as scaffolding for utterances (Bock, 1990; Bock \& Loebell, 1990). To the extent that these frames can be generated in abstract form, their use is not directly contingent on, or triggered by, lexical retrieval. The identities of the words selected to appear in any particular frame, in fact, need 
not matter to the early formulation process. This approach is instantiated in some connectionist models of structural processing by a dual-path architecture separating processes responsible for lexical semantics from processes responsible for form (e.g., Chang, Dell, \& Bock, 2006).

One way of conceptualizing the relative contributions of lexicalized and abstract syntax during speaking is in terms of the distinction between retrieval and construction (Jackendoff, 2002). Generally speaking, some elements of sentences (words, at a minimum) must be retrieved from a long-term store, but others (like many facets of grammatical agreement or clause attachment) must be constructed online. In some cases, speakers may retrieve multi-word phrases or entire utterances from long-term memory (Goldberg, 1995; Kuiper, 1996; Sprenger, Levelt, \& Kempen, 2006); in other cases, they create utterances they may have never heard or produced before. Lexical accounts emphasize the role of retrieved, item-specific syntactic information by positing that structural information is mainly retrieved via selection of the appropriate words; structural accounts assign more responsibility to processes that create abstract frames without explicit reliance on word retrieval. For our purposes, the issue is not one of retrieval versus construction, but whether the structural frames used during language production depend on lexical retrieval. Alternatively, whether structural frames are retrieved or constructed, they may be abstract and independent of the retrieval of specific words.

We addressed this question by examining the extent of abstract structural processing in the production of lexicalized expressions, sometimes called fixed expressions. Lexicalized expressions are complex phrases for which the relationship between individual lexical items and phrasal meaning is to a large degree arbitrary. The arbitrariness of this relationship is normally taken to mean that these expressions are similar to words in being stored and retrieved as units of some kind. The traditional, prototypical examples involve idioms like kick the bucket. By definition, the meaning of such an expression is the product of an idiosyncratic combination of specific lexical items (e.g., Wood, 1986). Speakers cannot retrieve and productively combine individual words online to create an idiomatic expression: Because the idiomatic meaning often diverges so much from the sum of its parts, production entails the retrieval of the expression as a lexical constellation of sorts. Replacing words within this constellation can radically change the interpretation of the entire phrase (Jackendoff, 2002). The peculiarity of idiomatic meanings is explicitly captured in various production accounts by positing unitary storage of idioms at the lexical-conceptual level, i.e., storage of the expression as an entry with its own lexical, semantic, and syntactic representations (e.g., Jackendoff, 1997, chap. 7; Sprenger et al., 2006).

Such approaches to the storage and retrieval of idioms have direct implications for the storage and retrieval of structural information. As multi-word expressions with different degrees of structural flexibility, idioms must be stored with specific details about how the components of the idiom can be arranged and can combine with other words in realizing the expressions (Jackendoff, 1997, chap. 7). For this to happen, structural information must be bound to the idiom in long-term memory. This information becomes available as that unit is retrieved during production, much like structural information for individual words becomes available at lemma retrieval during production of a literal expression. Sprenger et al. (2006), for example, proposed that the structural options for idioms, like verb subcategorizations, are stored in company with the idiom in the lexicon as a superlemma. This binding of structural information to idiomatic entries removes part of the burden from procedures assembling the individual words online in working memory, and shifts that responsibility into the lexicon. As such, structural processing for idioms becomes largely a matter of structural retrieval, with the structures that are associated with idioms stored separately from those stored with their component words. In Jackendoff's (1997) proposal, the lexical-conceptual representation for an idiom is stored along with its unique structural privileges; in Sprenger et al. (2006, p. 177) a superlemma "specifies the syntactic relationships between the individual lemmas, sometimes modifying the pre-existing syntactic options of the simple lemmas it dominates" and "renders the notion of phrasal frames unnecessary." On such proposals, then, the structures of idioms are stored in the lexicon separately from the structural privileges of their component words, and produced without assembling abstract phrasal frames.

It is important to emphasize that the lexicalization of syntax does not rule out structural flexibility. In fact, the need for structural flexibility in idioms is one of the motivations behind lexical accounts like those of Jackendoff $(1997,2002)$. The options for structural arrangement are stored in company 
with an idiom, in the same way that verb subcategorizations may be stored and used in production for nonidiomatic expressions (Pickering \& Branigan, 1998). Any limitations on the structural flexibility of the idiom are captured in its stored syntactic privileges, which can make an idiom less malleable syntactically (Sprenger et al., 2006) without eliminating the degree of flexibility that most idioms have. At the same time, however, the idiosyncratic mapping from meaning to structure for idioms means that the source (or locus) of structural flexibility for idioms is different than the source of structural flexibility for nonidioms, inasmuch as the syntactic privileges for idioms are encoded in specific links between lexical-conceptual structure and syntax, links that differ from those responsible for the syntactic privileges of nonidiomatic expressions.

In contrast, abstract structural accounts of syntactic processing do not place the burden of producing sentence structure on stored information (Bock, 1990; Chang et al., 2006). While admitting the importance of lexically specific information about structure, they do not give sole priority to the lexicon during the formulation process. For idioms this means that even if idiomatic expressions are stored in unitary form, their internal structure is accessible to and undergoes the type of generalized syntactic processing involved in both production and comprehension (Cutting \& Bock, 1997; Peterson, Burgess, Dell, \& Eberhard, 2001).

The widely assumed lexical character of idioms recommends them as a means for contrasting strong lexical and structural accounts of how syntax normally comes into play in language production. If the syntax of an idiom is represented separately from the syntax of a nonidiom, it calls on a different mapping to semantics, requires a different lexical entry, is associated with a different frequency, and so on. For example, because of obvious disparities in meaning, the syntax of an idiomatic expression like throw in the towel should be represented separately from the syntax of the same verb phrase used with its literal meaning, as in throw in the baseball. So, on a lexical account, production of the idiom and the nonidiom would call on different lexical entries with different structural representations, and the two types of expressions would undergo different types of structural processing. On the other hand, structural accounts predict a fundamental similarity in the structural processing carried out for lexicalized and nonlexicalized expressions, on grounds that abstract syntactic procedures are not sensitive to variations in lexical compositionality. We undertook a test of these predictions in the present work, focusing on the processes of language production and using structural priming as a method for tapping into its workings.

Structural priming is a technique used for eliciting structural persistence (Bock, 1986). Structural persistence itself involves the tendency to generalize structures from one sentence to another even when the wording of the sentences differs. For example, having produced a prepositional dative like The wealthy widow gave her Mercedes to the church, speakers are more likely to use the same structure when subsequently describing an unrelated pictured event (e.g., The grandfather is reading a story to his grandson). Conversely, following production of a double-object dative like The wealthy widow gave the church her Mercedes, there is an increase in the likelihood of using this structure in subsequent utterances (e.g., The grandfather is reading his grandson a story). These effects have been observed with different structures and in different paradigms (Bock \& Loebell, 1990; Branigan, Pickering, \& Cleland, 2000; Chang, Bock, \& Goldberg, 2003; Ferreira, 2003; Pickering \& Branigan, 1998; Potter \& Lombardi, 1998), over short and longer time intervals (Bock \& Griffin, 2000), as well as in spontaneous speech (Szmrecsanyi, 2005). The structural nature of the effects (as opposed to effects on linearization or word order only) is reflected in two other findings. When prime sentences have the same word-order but different constituent structures, priming effects trace the structural configuration (Bock \& Loebell, 1990, Experiment 3); when priming sentences have different word-orders but the same structure, priming effects are similar (Bock, Loebell, \& Morey, 1992; Pickering, Branigan, \& McClean, 2002).

The fact that these effects are not contingent upon lexical overlap of either content or function words (Bock, 1989; Hartsuiker, Pickering, \& Veltkamp, 2004; Loebell \& Bock, 2003) suggests that creating sentence structure makes use of procedures which can be, at least partially, deployed without lexical support. At the same time, when words are repeated between structures the likelihood of structural persistence increases substantially (Cleland \& Pickering, 2003; Pickering \& Branigan, 1998). This suggests that structural persistence is sensitive both to the abstract structural configurations of sentences and to the identities of lexical items used in these structures. This dual sensitivity makes it feasible to use structural priming to compare the relative magnitude of persistence from semantically 
transparent phrases (which we interchangeably call literal expressions or nonidioms, for short) to structurally matched phrases that are relatively opaque by virtue of their idiomaticity (which we call idioms, for short).

The lexical and structural accounts of syntactic processing sketched above make different predictions about the effectiveness of idiomatic and literal expressions as primes in a structural priming paradigm. A strong lexical account predicts that producing an idiom calls on a syntactic representation that belongs to the idiom. So, if syntactic processing is primarily steered by lexical retrieval, each instance of production of a strongly lexicalized verb phrase should be directed more by the lexicon and less by any abstract syntactic processes that might be involved in the production of structurally similar sentences with less lexicalized constellations of elements. This should limit the suitability of the phrase's structural scheme for other utterances. Consequently, the syntax of idioms may be less likely to generalize to subsequent sentences, reducing the effectiveness of these expressions as primes compared to literal expressions. Literal expressions, in contrast, consist of words that are more likely to be retrieved individually. By definition, expressions that exhibit full lexical combinatoriality are able to more readily enter into novel combinations: They can be assembled into syntactic forms on the fly according to the properties of each word separately. Such forms, and the processes that are responsible for creating them, should be more likely to generalize to sentences with new lexical items, and therefore more likely to create structural persistence. In short, if stored or lexicalized features of syntax normally dominate the production process, we expected reduced structural priming from idioms relative to literal expressions.

An abstract structuralist account predicts a different pattern. If structural processing is carried out mainly at a level that is abstract with respect to the lexicon, there should be little difference in the type of syntactic processing behind the production of literal and idiomatic expressions. Idioms may be retrieved as multi-word units because of their semantic compositionality, but the lexicalized nature of their representations should be of little consequence if syntactic mechanisms manipulate words as abstract symbols regardless of variations in the storage strength of lexical-syntactic pairings. Accordingly, lexically specific structural information should generalize across lexical items as easily as nonlexically specific structural information, and the two types of sentences should create comparable priming effects.

The structures used in the priming experiments below were phrasal verbs. Phrasal verbs are verbparticle combinations such as to throw [something] in. Most phrasal verbs allow the placement of the particle directly after the verb, e.g., A celebrity threw in a ball (post-verb particle) and after the direct object, e.g., A celebrity threw a ball in (post-object particle). This syntactic variability, the alternation between post-verb and post-object particles, should allow the construction to be influenced by priming.

Phrasal verbs have two other properties that were essential to this investigation. They vary in idiomaticity, ranging from nonidiomatic phrasal verbs in which the verb and particle make clearly separate contributions to the meaning of the phrase (e.g., to try [something] on or to let [somebody] in), to more semantically opaque verbs (e.g., to break [something] in orto live [something] down) where the relationship between the verb and the particle seems more arbitrary. For instance, the phrasal verb of a sentence like The hooligans pulled off the robbery is not a composite of the literal meanings of the verb pull and the particle off (Quirk, Greenbaum, Leech, \& Svartvik, 1972); instead, the expression receives its meaning from a semantically idiosyncratic verb-particle pairing that must be stored as a learned linguistic expression and retrieved as a unit during production. Second, phrasal verbs vary widely in their syntactic preferences. Some of them, idioms as well as nonidioms, are restricted to post-verb or post-object particles (e.g., give up the ghost; see relatives off), while others can be used with both constructions (e.g., pull off a robbery; pull a robbery off). These properties recommended phrasal verbs for studying how lexical and syntactic constraints come into play during sentence production.

In three experiments, participants read and recalled sentences shown on a computer screen using rapid serial visual presentation (RSVP; Chang et al., 2003; Potter \& Lombardi, 1990, 1998). We chose this method of presentation because of inherent difficulties in eliciting the desired structures through other means, such as picture description or sentence completion. In the RSVP task, sentences must be reconstructed from memory, and the reconstructed syntax of target sentences can be influenced by the structure of preceding sentences, creating structural persistence. Prime and target sentences con- 
tained verbs that were expressed either with post-verb or post-object particles, so target reconstruction was primed by both types of constructions. Participants were expected to produce more post-verb sentences following post-verb primes, and more post-object sentences following post-object primes.

Experiment 1 tested whether and how sensitively this alternation can be primed. Phrasal verbs have not been used in controlled studies of structural persistence, although corpus analyses of phrasal verbs suggest that particle placement should be susceptible to priming (Gries, 2005; Szmrecsanyi, 2004). In the second experiment, we examined whether structural persistence could be reliably elicited for idiomatic and nonidiomatic expressions that were syntactically frozen and syntactically flexible. In the third experiment, we turned to the priming patterns created by syntactically flexible phrasal verbs that differ in idiomaticity.

In Experiments 1 and 3, we also included assessments of the impact of lexical repetition on structural persistence. Structural priming is considerably strengthened when content words in a prime match those in the target (Pickering \& Branigan, 1998), a phenomenon termed the lexical boost. Because the lexical boost is a clear signature of specific lexical involvement in priming, its presence served as a litmus test to validate whether the priming we observed is in clear respects lexically mediated. The three experiments together tested whether and how a factor associated with the lexicalization of syntax, idiomaticity, affected the abstract generalization of syntax from one utterance to another.

\section{Experiment 1}

The purpose of Experiment 1 was to test whether the syntactic structure of phrasal verbs is amenable to priming in the RSVP task and to assess various boundary conditions on structural persistence for the verb-particle construction. On every trial, participants silently read a sentence from a computer screen, completed a distractor task, and then recalled the sentence aloud. The priming manipulation was implemented by pairing a prime sentence on one trial with a target sentence on the next trial; from the standpoint of participants, each of these trials appeared no different from the filler trials that surrounded them. Experimental sentences contained verbs which could place the particle after the verb (post-verb) or after the direct object (post-object), as in (1) and (2) below:

(1) A celebrity threw in the first ball. (post-verb)

(2) A celebrity threw the first ball in. (post-object)

Experimental items consisted of two sentences that served alternately as primes and targets for different participants. For each prime-target pairing the structure of the primes and targets was identical half of the time (with both the prime and the target having post-verb or post-object particles) and different the other half (with the post-verb and post-object particles alternating in the primes and targets). We expected that the structure of the primes would be recreated in target reconstruction, such that production of a post-object prime would increase the likelihood of post-object production on the target trial, and production of a post-verb prime would increase the likelihood of post-verb production on the target trial.

Although priming was not expected to be contingent upon metrical identity between primes and targets (Bock \& Loebell, 1990), there is some evidence from language comprehension that metrical properties may influence facets of structural persistence (Dooling, 1974). The verb-particle construction in particular is sensitive to the weight of the direct object: The tendency to place particles after objects co-varies with object heaviness (e.g., Arnold, Wasow, Losongco, \& Ginstrom, 2000; Lohse, Hawkins, \& Wasow, 2004; Szmrecsanyi, 2005). This made it worthwhile to examine the effects of object heaviness on persistence, to determine whether changes in direct-object length create different priming patterns for sentences with longer (heavier) and shorter (lighter) direct objects. To evaluate this possibility, we systematically varied the relative length of the objects in the primes and targets. It turned out that these variations had a negligible impact on priming, so our discussion of the data is cursory. However, the details of the manipulation are described in the methods sections of Experiments 1 and 3, and the results are summarized in the discussion of Experiment 3. 


\subsection{Method}

\subsubsection{Participants}

Ninety-six undergraduates at the University of Illinois participated in the experiment to partially fulfill a class requirement. All were native speakers of English. Thirteen were replaced because they failed to produce a minimum of $40 \%$ codable responses to experimental items. The mean number of codable items produced per participant was $76.3 \%$, with a range from $43.8 \%$ to $97.9 \%$.

\subsubsection{Materials}

A set of 96 phrasal verbs was selected from the English lexicon without regard to idiomaticity, with the constraint that each of the eight most frequently used particles (on, off, in, out, up, down, over, away) occurred equally often (12 times) in the set. One transitive sentence was written using each verb. Sentences were paired to create 48 experimental items in which the sentences served alternately as the prime (first sentence) and target (second sentence). Prime-target pairings were designed to avoid semantic overlap between the sentences. The pairs are listed in Appendix A, without the structural variations.

All primes and targets could be expressed with either post-verb or post-object particles, so each item appeared in four different syntactic conditions. In two conditions the structures of the primes and targets were identical and in two conditions they were different. Each structure of interest (post-verb and post-object) thus occurred equally often, with post-object particle positioning primed half the time and post-verb positioning primed the other half of the time. Table 1 gives an example of an item in all four versions. Four additional versions were created for each item by reversing the order of the primes and targets, giving a total of eight versions per item.

To survey heaviness and particle repetition effects on priming, 40 of the 48 items were distributed across five categories of eight items each, determined by the length of the sentences' direct objects and by particle repetition. Four categories were composed of sentences with direct objects of either equal or mismatched lengths (mean lengths appear in parentheses): (a) Short primes paired with short targets, direct objects of identical lengths (3.9 syllables); (b) long primes paired with long targets, direct objects of identical lengths (5.3 syllables); (c) short primes (3.0 syllables) with long targets (6.0 syllables); and (d) long primes (5.4 syllables) with short targets (3.0 syllables). (One item in category (b) and one in category (d) mistakenly included sentences that were shorter than intended; they are omitted from the syllable-length means and from the analyses below). A fifth category consisted of items in which the primes and targets contained verbs with identical particles; the average lengths of the direct objects in these items were similar, with 4.5 syllables in the primes and 4.1 syllables in the targets. The remaining 8 of the 48 items consisted of primes and targets whose direct objects were closely matched in length ( 2.8 and 2.9 syllables) and had infinitive constructions or material added to the ends of the sentences in order to add more variety to the prime and target pairs. (This set was not considered in the analyses of the length and repetition effects.)

Eight lists of the 48 items were created. Every item appeared in a different version across lists, and six different items appeared in each of the eight versions within lists. Thus, each participant saw only one version of each experimental item and six different items in each of the eight versions. Within lists, item order was constrained such that no more than two structurally similar primes followed one other, and targets alternated according to an ABAB scheme. For example, if any two consecutive items contained a post-verb prime, the following item had to contain a post-object prime; if any one

\section{Table 1}

Example of prime-target pairings for one item in post-object and post-verb priming conditions, Experiment 1

\begin{tabular}{lll}
\hline Condition & Prime & Target \\
\hline $\begin{array}{l}\text { Post-object primed } \\
\text { Post-verb primed }\end{array}$ & $\begin{array}{l}\text { The burglars broke the door down } \\
\text { The burglars broke down the door }\end{array}$ & The high prices scared off the customers (post-verb) \\
$\begin{array}{l}\text { Post-object primed } \\
\text { Post-verb primed }\end{array}$ & $\begin{array}{l}\text { The burglars broke the door down } \\
\text { The burglars broke down the door }\end{array}$ & The high prices scared the customers off (post-object) \\
\hline
\end{tabular}


item contained a post-verb target, the following item had to contain a post-object target. This sequence of 48 items was divided into eight blocks of equal length, which were rotated through the lists to minimize practice effects.

Experimental items were separated by filler sentences, which had a variety of syntactic structures (e.g., intransitive, cleft, copula, and infinitival complement constructions). None of them contained phrasal verbs. Five fillers separated every experimental sequence from its neighbors in order to minimize the chances of participants noticing the manipulation of phrasal verbs. Two additional fillers appeared at the beginning of each list as practice items, yielding 242 fillers per list. All fillers occupied the same positions on all lists, and were arranged so as to avoid semantic similarity or pragmatic continuity between adjacent sentences. The filler-sentence trials proceeded in exactly the same way as the individual prime-sentence and target-sentence trials, making the experimental trials indistinguishable from the fillers. In total, each participant was presented with a list of 338 apparently unrelated sentences, one on each trial.

\subsubsection{Procedure}

Participants were tested in individual sessions on a Macintosh Quadra 650 running PsyScope software (Cohen, MacWhinney, Flatt, \& Provost, 1993). They were randomly assigned to one of the eight lists. Instructions for the experiment appeared on the screen, and were additionally paraphrased by the experimenter before beginning the experiment. Participants were told that they would see a number of sentences (trials) and would perform two tasks on each trial: remembering the sentence and doing a distractor task. The sequence of events for each trial is illustrated in Fig. 1 (adapted from Chang et al., 2003).

Each trial began with a $200 \mathrm{~ms}$ fixation prompt consisting of asterisks displayed in the center of the screen. Next, a sentence was presented one word at a time. Each word appeared on the screen for $100 \mathrm{~ms}$ with a $0 \mathrm{~ms}$ interstimulus interval. Participants were instructed to read the sentence silently and try to remember it as best they could in order to recall it later.

\begin{tabular}{|c|c|}
\hline Duration & Event \\
\hline $200 \mathrm{msec}$ & \multirow{13}{*}{$\begin{array}{c}\text { ********* } \\
\text { A } \\
\text { proctor } \\
\text { handed } \\
\text { out } \\
\text { the } \\
\text { exams. } \\
\text { \#\#\#\#\#\#\#\#\# } \\
45291 \\
\text { (screen blanked) } \\
\text { two } \\
\text { (screen blanked) } \\
\text { No Yes } \\
\end{array}$} \\
\hline $100 \mathrm{msec}$ & \\
\hline $100 \mathrm{msec}$ & \\
\hline $100 \mathrm{msec}$ & \\
\hline $100 \mathrm{msec}$ & \\
\hline $100 \mathrm{msec}$ & \\
\hline $100 \mathrm{msec}$ & \\
\hline $100 \mathrm{msec}$ & \\
\hline $533 \mathrm{msec}$ & \\
\hline $100 \mathrm{msec}$ & \\
\hline $500 \mathrm{msec}$ & \\
\hline \multirow[t]{2}{*}{$10 \mathrm{msec}$} & \\
\hline & \\
\hline $500 \mathrm{msec}$ & $\odot$ \\
\hline \multicolumn{2}{|r|}{$\begin{array}{c}\text { Repeat } \\
\stackrel{\bullet}{\bullet} \\
\text { • }\end{array}$} \\
\hline
\end{tabular}

Fig. 1. Sequence of events during every trial. 
To obstruct rehearsal of the sentence, participants then performed a numerical distractor task. An array of five single digits was displayed on the screen for $533 \mathrm{~ms}$, followed by a number written out as a word, displayed for $500 \mathrm{~ms}$. Participants were prompted to decide whether or not they had seen this number in the original array of five digits. They responded by pressing the yes or no button on a button box under no time constraint, and received immediate feedback: a happy face (correct) or a sad face (incorrect) depending on the response they had given.

On filler trials, correct responses to the distractor task included both the yes andno button presses, and the to-be-verified number could appear anywhere within the array of five digits. On experimental trials, correct responses to distractors were always affirmative and the to-be-verified number appeared as either the leftmost or rightmost digit in the array. These steps were designed to minimize extraneous sources of variability in performance on experimental trials.

After the distractor task, the word Repeat appeared on the screen prompting participants to produce the sentence they had read at the beginning of the trial. Responses were recorded through a head-worn Shure microphone on a Sony Digital Audio Tape Deck and transcribed online by an experimenter sitting in the room. After producing the sentence, participants pressed a button to go on to the next trial. One trial took approximately 6-8 s to complete and the entire session lasted about $45 \mathrm{~min}$. Transcriptions were later checked for accuracy against the recordings.

\subsubsection{Scoring}

All recalled sentences were scored as having post-verb particles, post-object particles, or as incorrect. Sentences were considered incorrect when the particle or the direct object was omitted, when the direct object was replaced by a pronoun, when the entire sentence was turned into a passive or an intransitive construction, or when the sentence was not recalled at all. Sentences with minor changes in content words (synonym substitutions or substitutions of members of the same category, e.g., reports for documents, manager for owner, send out for send in, or omission of adjectives, possessives or articles from the direct objects) were scored as correct for the purposes of the primary analyses.

The sentences produced on target trials were scored only if their primes had been recalled with the phrasal-verb syntax in which they were originally presented. If the prime was recalled in the alternative construction (i.e., with a post-verb particle when a post-object particle was originally presented, or vice versa), the prime was scored as transformed. Primes were transformed during reproduction on $11.6 \%$ of all trials, and these trials were excluded from the final analyses. (Trials where the prime sentence was reproduced with the alternative structure and the target sentence was reproduced incorrectly counted towards the $40 \%$ cutoff but are included in the "transformed prime" category for ease of exposition. The same is true in the subsequent experiments.) The majority of transformations were cases of post-object primes being reconstructed with post-verb syntax (400 sentences out of 534), consistent with speakers' a priori preference for post-verb syntax for most of the sentences (and consistent with conversational usage; Szmrecsanyi, 2004). Additional trials were excluded from the final analyses because either the primes (12.9\%) or the targets (9.0\%) were produced incorrectly (see Table 2 for the distribution of rejected trials across conditions). Analyses were performed on the remaining scorable 3068 trials (66.6\% of all responses).

\subsubsection{Design and analyses}

Every participant received 12 items in each of the four cells formed by crossing prime structure (post-verb vs. post-object) and target structure (post-verb vs. post-object). Every item was seen by 24 participants in each of the four cells of the design. The primary dependent variable for all analyses was the proportion of post-object constructions out of all post-verb and post-object sentences produced on target trials in each of the four cells of the design. Proportions were calculated for each participant and each item by dividing the number of produced post-object sentences by the total number of scorable responses in that cell.

Two-factor repeated measures analyses of variance were conducted on arc-sine transformed proportions, treating participants $\left(F_{1}\right)$ and items $\left(F_{2}\right)$ as random factors, with prime structure and target structure crossed within participants and within items. $\operatorname{Min} F^{\prime}$ was calculated where possible, following Clark (1973). In this and subsequent experiments, effects were considered to be significant when 
Table 2

Distribution of rejected trials by condition in Experiments 1, 2, and 3

\begin{tabular}{|c|c|c|c|c|c|}
\hline \multirow{2}{*}{$\begin{array}{l}\text { Presented prime } \\
\text { form }\end{array}$} & \multirow{2}{*}{$\begin{array}{l}\text { Presented target } \\
\text { form }\end{array}$} & \multirow{2}{*}{$\begin{array}{l}\text { Transformed prime } \\
\text { (alternate structure) }\end{array}$} & \multicolumn{2}{|c|}{ Counts of rejected trials } & \multirow[t]{2}{*}{ Total (\%) } \\
\hline & & & $\begin{array}{l}\text { Incorrect prime } \\
\text { produced }\end{array}$ & $\begin{array}{l}\text { Incorrect target } \\
\text { produced }\end{array}$ & \\
\hline \multicolumn{6}{|l|}{ Experiment 1} \\
\hline Post-verb & Post-verb & 73 & 144 & 119 & $336(22)$ \\
\hline Post-object & Post-verb & 200 & 154 & 76 & $430(28)$ \\
\hline Post-verb & Post-object & 61 & 154 & 125 & $340(22)$ \\
\hline Post-object & Post-object & 200 & 141 & 93 & $434(28)$ \\
\hline \multicolumn{6}{|l|}{ Experiment 2} \\
\hline Post-verb & Post-verb & 14 & 68 & 31 & 113 (19) \\
\hline Post-object & Post-verb & 41 & 99 & 46 & $186(32)$ \\
\hline Post-verb & Post-object & 14 & 67 & 31 & $112(19)$ \\
\hline Post-object & Post-object & 43 & 97 & 32 & $172(30)$ \\
\hline \multicolumn{6}{|l|}{ Experiment 3} \\
\hline Post-verb & Post-verb & 36 & 85 & 92 & $213(23)$ \\
\hline Post-object & Post-verb & 109 & 94 & 73 & $276(29)$ \\
\hline Post-verb & Post-object & 30 & 95 & 63 & $188(20)$ \\
\hline Post-object & Post-object & 100 & 99 & 69 & $268(28)$ \\
\hline
\end{tabular}

associated with probabilities less than or equal to .05. Figures show overall proportions either with standard errors or with the confidence intervals for the differences between the post-object and post-verb priming conditions obtained from an analysis by participants performed on untransformed data.

\subsection{Results}

The overall proportions of post-object sentences produced in each condition are listed in Table 3 . Fig. 2 shows that participants were more likely to produce post-object sentences after post-object primes (.47) than after post-verb primes (.41). Statistical analyses confirmed this pattern, with a significant main effect of prime type, $F_{1}(1,94)=4.46, F_{2}(1,94)=18.42, \min F^{\prime}(1,137)=3.59$. (There was one empty cell in the analysis by participants and one in the analysis by items, reducing the corresponding degrees of freedom.) The analysis also showed a main effect of target type, indicating simply that participants tended to reproduce the syntactic structure of the target sentences they had seen. After post-object primes, .81 of the recalled target sentences had post-object particles; after post-verb primes, .07 of the recalled targets had post-object particles, $F_{1}(1,94)=570.96, F_{2}(1,94)=863.24, \min F^{\prime}$ $(1,181)=343.66$.

Target sentences originally presented with post-verb particles were $5 \%$ more likely to be reconstructed with post-object particles when post-object particles were primed than when they were not, whereas target sentences originally presented with post-object particles were $8 \%$ more likely to be reconstructed with post-object particles when this structure was primed than when it was not. This yielded an interaction between prime and target form that was marginal by participants but significant by items, $F_{1}(1,94)=.09, F_{2}(1,94)=9.55, \min F^{\prime}(1,96)=.09$.

\subsubsection{Phrase-length effects}

Direct-object heaviness mattered little to priming. This was assessed by comparing the persistence patterns across the four sets of items that manipulated relative length of the direct object. The counterbalancing of the order of the primes and targets caused items containing sentences of unequal lengths to change length conditions (e.g., an item with a long prime and short target in one order had a short prime and a long target in another order), so the alternate orders were treated as different items. The data were analyzed only by items because these pairings were not counterbalanced within participants. We considered only responses that preserved the relative differences in the lengths of the primes and targets and did not introduce lexical overlap, setting aside 280 cases when length changed and seven cases when overlap occurred. This left 1717 responses. 
Table 3

Proportions of post-object sentences (with total numbers of scored sentences per cell) produced after priming in Experiments 1, 2, and 3

\begin{tabular}{|c|c|c|}
\hline \multirow[t]{2}{*}{ Priming condition (and verb form) } & \multicolumn{2}{|c|}{ Target form presented } \\
\hline & Post-verb & Post-object \\
\hline \multicolumn{3}{|l|}{ Experiment 1} \\
\hline Post-object primed & $.10(722)$ & $.85(718)$ \\
\hline Post-verb primed & $.05(816)$ & $.78(812)$ \\
\hline \multicolumn{3}{|l|}{ Experiment 2} \\
\hline Post-object primed & $.06(326)$ & $.89(340)$ \\
\hline Post-verb primed & $.02(399)$ & $.81(400)$ \\
\hline \multicolumn{3}{|l|}{ Experiment 3} \\
\hline Post-object primed & $.09(492)$ & $.85(500)$ \\
\hline Post-verb primed & $.03(555)$ & $.79(580)$ \\
\hline
\end{tabular}

Table 4 shows the overall proportions of post-object sentences produced in the post-object and post-verb priming conditions across the four length pairings. An analysis of variance was carried out on the priming effect (the difference between post-object and post-verb priming) for the items in each length category, so prime and target length were varied between items. There were no significant effects of prime or target length (respectively, $F_{2}(1,56)=.59$ and $F_{2}(1,56)=3.04, p=.09$ ) and no interaction $\left(F_{2}(1,56)=.07\right)$.

The only notable effect of variations in phrase length was on prime reproduction. As the prime sentences' direct objects increased in length, participants were more likely to change sentences presented with post-object particles into sentences with post-verb particles. Among prime sentences with direct objects of seven or more syllables, $89 \%$ of the transformations moved the particles from after the object to after the verb; in contrast, among prime sentences with direct objects of two or fewer syllables, $58 \%$ of the transformations moved the particles from post-object to post-verb position. So, particles tended to be moved close to the verb more often when the direct objects were long than when the direct objects were short. This aligns with the preference for light-then-heavy word-order in production.

\subsubsection{Particle repetition and priming}

We assessed the effect of particle repetition on priming by comparing priming for the 16 items with repeated particles to priming for the 80 items in which there was no lexical overlap. There were 35 responses in which prime or target reproductions introduced or eliminated lexical overlap, and these were removed from the comparison. Items with particle repetition yielded numerically stronger priming effects than items without repetition (.09 vs. .06), but this difference was not significant in an items analysis, $t(94)=.80$.

\subsection{Discussion}

Experiment 1 showed that participants made use of primed verb-particle syntax when reconstructing target sentences, producing more post-object sentences following post-object primes and more post-verb sentences following post-verb primes. Particle placement in phrasal verbs is thus sensitive to controlled priming manipulations in the RSVP task.

The items in Experiment 1 included a mixture of idiomatic and nonidiomatic expressions. As a preliminary exploration of whether the priming patterns varied as a function of the idiomaticity of the verbs used in the priming sentence, we compared the persistence effects for the items with idiomatic primes (38 items) to those for the items with nonidiomatic primes (58 items), omitting 18 responses (1\%) in which the idiomaticity of the verb in the reproduction differed from the idiomaticity of the verb in the presented sentence (e.g., the idiomatic lead on reproduced as the nonidiomatic lead out). Categorization of verbs as idiomatic and nonidiomatic was based on experimenter judgments and on norms collected for Experiments 2 and 3. The overall priming effects for idiomatic and nonidiom- 


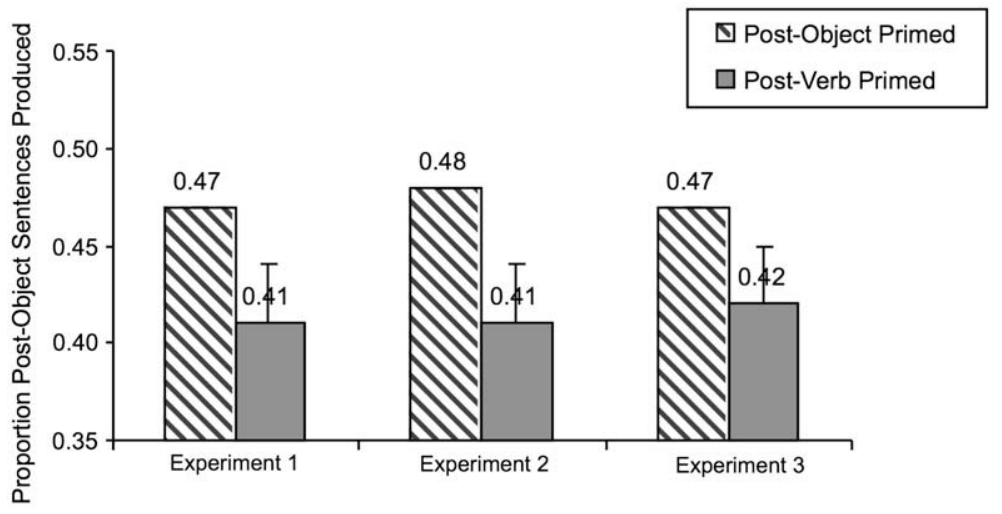

Fig. 2. Proportions of post-object sentences produced after post-object and post-verb primes in Experiments 1, 2, and 3 (error bars represent $95 \%$ confidence intervals for differences between priming conditions calculated from error terms in analyses with prime and target form as the only factors).

Table 4

Direct-object heaviness effects on priming, Experiments 1 and 3: proportions of post-object-particle placements after post-objectparticle primes and post-verb-particle primes for short and long direct objects

\begin{tabular}{|c|c|c|}
\hline & \multicolumn{2}{|l|}{ Priming condition } \\
\hline & Post-object form primed & Post-verb form primed \\
\hline Prime-target pairing & Experiment 1 & \\
\hline Short prime/Long target & .48 & .43 \\
\hline Long prime/Short target & .43 & .40 \\
\hline Short prime/Short target & .44 & .43 \\
\hline \multirow[t]{2}{*}{ Long prime/Long target } & .47 & .37 \\
\hline & Experiment 3 & \\
\hline Short prime/Long target & .45 & .39 \\
\hline Long prime/Short target & .51 & .50 \\
\hline Equal-length primes and targets & .57 & .47 \\
\hline
\end{tabular}

atic items were $7.2 \%$ vs. 5.4\%, suggesting that idiomaticity did not disrupt normal persistence. Experiments 2 and 3 evaluated this under more stringent conditions.

Particle repetition also did not affect priming. This is consistent with other results in the priming literature that show repetition of closed-class elements between primes and targets to be ineffective at inducing persistence (cf. Bock, 1989; Pickering \& Branigan, 1998). Since phrasal verbs include both a verb and a particle, it may be necessary for both to be repeated in order for the lexical boost to operate. Experiment 3 revisited this.

Direct-object heaviness mattered only to the reproduction errors in the primes. The error pattern showed that normal length constraints on production were at work in the experiment. However, variations in length between primes and targets did not alter the priming effects.

\section{Experiment 2}

Experiment 1 established that alternative forms of the verb-particle construction can be primed and suggested that the effects do not depend on the identity of particles in the verbs. This makes verb-particle constructions similar to other sentence types for which persistence has been demonstrated. Experiment 1 also provided a small piece of evidence suggesting that the priming patterns created by idiomatic and nonidiomatic expression might be similar. Experiments 2 and 3 turned expressly to the question of whether idiomatic and nonidiomatic verb-particle expressions differ in their ability to prime alternative structures. 
Experiment 2 used sentences containing idiomatic and nonidiomatic phrasal verbs as primes, with the idiomaticity of the verbs confirmed by norming. Structural priming from idioms was compared to priming from the nonidioms to estimate their relative priming ability. In general, lexicalist and abstractionist accounts of structural formulation make different predictions about the consequences of idiomaticity for the generalization of sentence structure. Strong lexical accounts predict an interaction between idiomaticity and priming ability, with idioms being less effective primes than nonidioms, since the latter are more likely to share a mapping from lexical-conceptual structure to syntactic structure with many other verbs. Strong structural accounts, in contrast, predict little impact of variations in idiomaticity on the magnitude of structural persistence, on the argument that an abstract phrasal frame is needed for the production of idioms and nonidioms alike.

Experiment 2 also looked at whether syntactic inflexibility, a stereotypical property of idioms, matters to structural priming. Although inflexibility is sometimes associated with idiomaticity, it is neither a necessary nor a sufficient condition (Nunberg, Sag, \& Wasow, 1994). In fact, idioms can be flexible and nonidioms can be inflexible. For instance, the nonidiomatic post-object construction ask someone in has no post-verb counterpart (ask in someone is at best odd, on its own; making it acceptable demands a fairly long direct object). Accordingly, in Experiment 2 we included flexible and inflexible nonidioms as well as flexible and inflexible idioms. We manipulated flexibility and idiomaticity orthogonally by using idiomatic and nonidiomatic prime sentences that were strongly polarized in the degree to which they admitted alternations, and compared these to idiomatic and nonidiomatic prime sentences that could freely appear in both structures of interest.

On lexicalist proposals (e.g., Jackendoff, 1997; Sprenger et al., 2006) the direct source of reduced flexibility in idioms is their stored lexical-syntactic structure. Specifically, the lexical-conceptual structure of the idiom maps onto a syntactic structure that lacks the full potential of structurally similar nonidiomatic expressions. In addition, the mapping from the lexical-conceptual to the syntactic representation may be implicated in structural inflexibility, due to a hypothesized relationship between semantic compositionality and syntactic productivity (Gibbs \& Gonzales, 1985; Gibbs, Nayak, Bolton, \& Keppel, 1989; Gibbs, Nayak, \& Cutting, 1989; Jackendoff, 1997; Nunberg et al., 1994): The more independent the meaning of an idiom is from the individual meanings of an idiom's words or phrases, the less syntactically productive the idiom will be. If the interaction of these factors creates powerful restrictions on structural generalizations from idiomatic primes, an aberrant (i.e., idiomatic) meaning coupled with a limited set of structural privileges may drive substantially reduced structural priming.

\subsection{Method}

\subsubsection{Participants}

In the main experiment there were 128 undergraduates from the same source as Experiment 1, all native speakers of English. The final group of 128 included 21 replacements for participants who produced less than $37.5 \%$ codable responses to experimental items (nine of these served to fully counterbalance the design), two replacements for inability to perform the task, and four replacements for experimenter errors. The mean number of codable items produced per participant was $79.8 \%$, with a range from $37.5 \%$ to $100 \%$.

\subsubsection{Materials}

Sixteen experimental items were constructed by pairing 16 nonidiomatic targets with eight idiomatic and eight nonidiomatic primes, with half of each type being frozen and half flexible (see Table 5 for examples and Appendix B for the complete list). A phrasal verb was considered to be idiomatic if the meaning of the verb-particle construction was different from the literal meaning of the primary verb and could not be readily derived from its constituent parts (Quirk et al., 1972), as in break in your boots and put up some refugees. In nonidiomatic phrasal verbs, the meaning of the entire construction could be derived directly from the literal meanings of their verbs and particles, as in ask the reporters in and wake up the residents. These properties were confirmed by norming (see below). Flexibility of the expressions was determined by whether the placement of the particle either after the verb or after the 
Table 5

Examples of prime and target types in Experiment 2

\begin{tabular}{ll}
\hline Prime types and examples & Target types and examples \\
\hline Idiomatic frozen post-verb structure & Nonidiomatic post-verb structure \\
The New York Mets brought up the rear & The toddler threw away one of his toys \\
Idiomatic frozen post-object structure & Nonidiomatic post-object structure \\
The crooked salesman couldn't take the customer in & The toddler threw one of his toys away \\
Idiomatic flexible post-verb structure & \\
The teenager shot off his mouth & \\
Idiomatic flexible post-object structure & \\
The hotel put some of the refugees up & \\
Nonidiomatic frozen post-verb structure & \\
The new material gave off a weird smell & \\
Nonidiomatic frozen post-object structure & \\
The ambassador finally asked all the reporters in & \\
Nonidiomatic flexible post-verb structure & \\
Judy snapped on her earrings & \\
Nonidiomatic flexible post-object structure & \\
The graduating senior sent his application in &
\end{tabular}

direct object was fixed by linguistic convention (assessed largely through web searches and confirmed with norming).

The number of primes, 16 in all, was small because very few phrasal verbs in the English lexicon meet the fully frozen criterion, and the aim of the experiment made it important to maximize the combination of idiomaticity with flexibility. Half of the frozen primes (four idiomatic and four nonidiomatic) had verbs which required post-verb particle placement and the other half had verbs that required post-object particle placement. Flexible primes were sentences in which the placement of the particle could in principle vary, but for the purposes of the experimental design, half of these primes were arbitrarily designated to appear only with post-verb particles and half with post-object particles.

Prime flexibility was necessarily manipulated between items, because the syntactic structure of the frozen primes could not be varied. In addition, because the prime sentences did not vary in syntax, there was no reversal of the order of the primes and targets in this experiment.

To minimize the effects of idiosyncratic prime-target interactions, 16 parallel versions of the prime and target pairings were constructed. In the first pairing, each of the 16 prime forms was combined with one of the structural forms of a single target, the post-verb particle form or the post-object particle form, so that every prime occurred once, every target appeared once in one of its two forms, and the target forms were equally divided between the post-verb and post-object forms. The second pairing was created by combining the prime with the alternate form of the same target. The remaining pairings were created by successively recombining all 16 primes with a different target to put the target into a different cell of the design. Thus, every target in both of its structural variations appeared once with a prime from each of the eight combinations of idiomaticity, flexibility, and structural form.

There were 16 presentation lists, each constructed using one of the 16 different prime-target pairings. All of the lists contained 16 experimental items, one item for every unique prime and target pairing and an equal number of items containing targets in the post-verb or post-object form. Every list therefore contained one item representing the 16 combinations of prime type (idiomatic or nonidiomatic, flexible or frozen, post-verb particle or post-object particle) with target type (post-verb particle or post-object particle). Across the 16 lists, every target appeared 8 times in its post-verb form and 8 times in its post-object form. Thus, each participant saw only one version of each item, one in each of the 16 conditions.

The experimental items, each composed of two sentences, were combined in presentation lists with 168 filler sentences that occurred in the same positions in all lists (160 of these were unrelated to the experimental items and the remainder were phrasal-verb forms included to evaluate corpus estimates of preferences; the results from the latter were unremarkable and will not be discussed further). Experimental items were separated by a minimum of eight fillers. The presentation lists were divided into four blocks, rotated across participants in a counterbalanced fashion to distribute practice 
and fatigue effects. In total, each participant read and recalled 202 apparently unrelated sentences, one on each trial.

\subsubsection{Item norming}

Ratings were collected for all the experimental primes and targets on the idiomaticity of their verbs and the acceptability of the post-verb and post-object versions of each sentence. To obtain idiomaticity judgments, 34 participants were given all 64 experimental sentences and asked to rate the idiomaticity of the phrasal verbs in these sentences on a 7-point scale ( $1=$ "not idiomatic", $7=$ "highly idiomatic"). The instructions defined idiomatic phrasal verbs as expressions whose common or "dictionary" meaning could not be used to guess their contribution to the meaning of the sentences they were used in. All verbs appeared with post-verb syntax, with the exception of the frozen verbs taking post-object syntax by convention. (Idiomaticity ratings for both the post-verb and post-object versions of the flexible forms were collected in Experiment 3. In Experiment 3 norming, post-object versions of the items used in the present experiment received idiomaticity ratings nearly identical to the ratings for the corresponding post-verb versions.)

Results appear in Table 6 for each item type separately. All 16 target sentences used in the experiment were nonidiomatic and received correspondingly low ratings on the idiomaticity scale $(M=2.70)$. In the prime sentences, the eight idiomatic verbs were rated higher in idiomaticity $(M=5.10$, range $=3.71-6.09)$ than the eight nonidiomatic verbs $(M=2.78$, range $=2.03-4.15)$. There was little difference between the idiomaticity ratings of flexible $(M=3.63$, range $=2.03-6.09)$ and frozen primes $(M=4.24$, range $=2.56-5.29)$, and little difference between the ratings of primes appearing with post-verb syntax $(M=4.11$, range $=2.26-6.09)$ and post-object syntax $(M=3.77$, range $=2.03-$ 5.44). These differences were tested in a 2 (idiom vs. nonidiom) $\times 2$ (flexible vs. inflexible) $\times 2$ (post-verb vs. post-object) between-items analysis of variance which showed a main effect of idiomaticity, $F(1,8)=49.17$, a marginal effect of structural flexibility, $F(1,8)=3.73, p=.10$, no main effect of rated structure, $F(1,8)=1.03$, and no interactions.

Ratings of acceptability were collected from 64 other participants. They were asked to rate how natural each of the 32 experimental sentences sounded to them on a 7-point scale ( $1=$ "not natural at all," 7 = "very natural") with both post-verb and post-object particles. Each participant received an equal number of sentences in post-verb (4 idiomatic, 12 nonidiomatic) and post-object (4 idiomatic, 12 nonidiomatic) forms, interspersed among 40 filler sentences.

Results are shown in Table 7. Frozen forms received higher preference ratings in their expected structures (i.e., in their frozen versions) than in the alternative form (4.64 vs. 3.28), and the absolute preference difference between the post-verb and post-object forms was greater overall for frozen than for flexible primes (1.36 vs. .60). Comparing the preference effects (the difference between the post-

\section{Table 6}

Idiomaticity ratings for materials in Experiment 2

\begin{tabular}{|c|c|c|c|c|}
\hline \multicolumn{5}{|c|}{ Properties of sentences used in experiment } \\
\hline Flexibility & Structure & Idiomaticity & Rated idiomaticity & Idiom-nonidiom difference and $95 \%$ confidence interval \\
\hline \multicolumn{5}{|l|}{ Prime verbs } \\
\hline \multirow{4}{*}{ Frozen } & Post-verb & Idiom & 5.27 & $1.42 \pm 1.27$ \\
\hline & & Nonidiom & 3.85 & \\
\hline & Post-object & Idiom & 5.07 & $2.31 \pm 1.60$ \\
\hline & & Nonidiom & 2.76 & \\
\hline \multirow[t]{4}{*}{ Flexible } & Post-verb & Idiom & $4.90^{\mathrm{a}}$ & $2.50 \pm 5.16$ \\
\hline & & Nonidiom & 2.40 & \\
\hline & Post-object & Idiom & 5.15 & $3.06 \pm 1.29$ \\
\hline & & Nonidiom & 2.09 & \\
\hline \multicolumn{5}{|l|}{ Target verbs } \\
\hline Flexible & Both & Nonidiom & 2.70 & \\
\hline
\end{tabular}

\footnotetext{
${ }^{\text {a }}$ Note. Ratings for the flexible post-verb items were much more variable than in Experiment 3, making the idiom-nonidiom contrast in this category nonsignificant.
} 
Table 7

Acceptability ratings for materials in Experiment 2

\begin{tabular}{|c|c|c|c|c|c|}
\hline \multicolumn{3}{|c|}{ Properties of sentences used in experiment } & \multicolumn{3}{|c|}{ Rated structure } \\
\hline Flexibility & Form presented & Idiomaticity & Post-verb & Post-object & Structure acceptability difference \\
\hline \multicolumn{6}{|l|}{ Prime verbs } \\
\hline \multirow[t]{4}{*}{ Frozen } & Post-verb & Idiom & 3.88 & 2.77 & 1.11 \\
\hline & & Nonidiom & 5.80 & 3.09 & 2.71 \\
\hline & Post-object & Idiom & 3.52 & 4.16 & -.64 \\
\hline & & Nonidiom & 3.75 & 4.72 & -.97 \\
\hline \multirow[t]{4}{*}{ Flexible } & Post-verb & Idiom & 3.89 & 4.42 & -.53 \\
\hline & & Nonidiom & 5.50 & 5.22 & .28 \\
\hline & Post-object & Idioms & 5.05 & 4.23 & .81 \\
\hline & & Nonidiom & 5.83 & 5.05 & .78 \\
\hline \multicolumn{6}{|l|}{ Target verbs } \\
\hline Flexible & Both & Nonidiom & 5.75 & 4.90 & .84 \\
\hline
\end{tabular}

Note. Each cell is the mean of two items.

verb and post-object ratings) for the frozen and flexible post-verb forms of the priming sentences, the preference effect for the frozen post-verb forms was 1.91, while the preference effect for the flexible post-verb forms was $-.13, t(6)=3.20$, with a $95 \%$ confidence interval for the difference between means of \pm 1.56 . For the post-object prime forms, the preference effect was -.80 for the frozen forms and .80 for the flexible forms, $t(6)=4.61$ and a $95 \%$ confidence interval for the difference of \pm .85 . For target sentences, acceptability was higher for the post-verb than the post-object structures (5.75 vs. 4.90).

\subsubsection{Procedure}

The procedure was identical to that described for Experiment 1. Each session took approximately 30 min to complete.

\subsubsection{Scoring}

Scoring criteria were the same as those used in the first experiment, with the addition of another type of incorrect response resulting from changes in the idiomaticity or flexibility of the reproduced sentence. The distribution of rejected trials by condition was similar to Experiment 1 and is shown in Table 2. A total of 112 responses (5.5\% of all trials) were excluded because the prime was reconstructed in the alternate structure. Again, the vast majority of the transformed trials were cases of post-object primes being reconstructed with post-verb syntax (84 sentences out of the 112). Another $16.1 \%$ of all trials (331 responses) were excluded because the prime was produced incorrectly, according to the criteria listed in Experiment 1, and 6.8\% (or 140 responses) were excluded because the target was produced incorrectly. These exclusions encompassed 69 responses in which participants reproduced primes with a verb that was unlike the original in either flexibility or idiomaticity (e.g., by reconstructing a sentence with a new flexible verb instead of the original syntactically frozen phrasal verb), or because either the prime or target was reproduced with a new verb that introduced lexical overlap. Analyses were performed on the remaining scorable $71.5 \%$ of all trials (1465 responses).

\subsubsection{Design and analyses}

Because of the restricted number of items, each participant saw only one item of each kind in each condition. This precluded analyses using individual participants as the random factor. Consequently, we pooled data to produce supersubjects (Ratcliff, Thapar, Gomez, \& McKoon, 2004), creating a single supersubject from four participants run on four different rotations of the same list. This yielded 32 supersubjects. Since all participants were drawn from the same population and assigned to lists randomly, analyses carried out with supersubjects as a random factor allow the same inferences to the population as analyses with individual participants.

Each of the 32 supersubjects received four items in each cell of the design. The data were analyzed in a within-participant (i.e., within-supersubject) analysis of variance that crossed the four factors of 
prime structure (post-verb vs. post-object), target structure (post-verb vs. post-object), prime idiomaticity (idiomatic vs. nonidiomatic), and prime flexibility (frozen vs. flexible).

Each of the 16 targets, once in each of its forms, was paired with eight different primes. Treating the two forms of each target as a single item, each item appeared twice in each of the 16 cells of a withinitems design formed by crossing the factors of prime form, target form, prime idiomaticity, and prime flexibility. Every item was presented to two supersubjects in each cell of this design.

Analyses of the data were carried out in two steps. We first assessed priming effects in analyses of variance that included prime form and target form as independent variables, pooling the data for prime flexibility and idiomaticity. The dependent variable in these analyses was the proportion of post-object sentences produced out of all scorable responses combined. We then looked at idiom and flexibility effects in analyses of variance that used the difference between post-object and postverb priming (a priming effect score) as the dependent variable, with the independent variables of prime idiomaticity and prime flexibility. Analyses treating participants and items as random effects were performed as in Experiment 1.

\subsection{Results}

\subsubsection{General priming effects}

The overall proportions and raw counts of post-verb and post-object sentences produced in each condition appear in Table 3, and the general priming effect is depicted in Fig. 2. Participants produced more post-object sentences following post-object primes (.48) than following post-verb primes $(.41)$, $F_{1}(1,31)=16.85, F_{2}(1,15)=13.18, \operatorname{minF}^{\prime}(1,37)=7.40$. There was a strong tendency to reuse the structure of the target sentences they had seen, producing .85 post-object constructions having received a post-object target and only .04 post-object constructions having received a post-verb target, $F_{1}(1,31)=731.44, F_{2}(1,15)=241.21, \min ^{\prime}(1,25)=181.39$. There was also a larger priming effect for post-object than for post-verb targets (.08 vs. .04 , respectively), $F_{1}(1,31)=8.51, F_{2}(1,15)=5.34$, $\min F^{\prime}(1,33)=3.28$.

\subsubsection{Flexibility and idiomaticity effects}

The critical comparisons were for priming occurring with the flexible and frozen idiom and nonidiom primes. Fig. 3 plots these effects for the post-object sentences produced in each combination of idiomaticity and flexibility. Priming from nonidioms was numerically stronger than priming from idioms (.08 vs. .05) but the effect was not significant $\left(F_{1}(1,31)=0.87, F_{2}(1,15)=0.35\right)$. Flexible primes

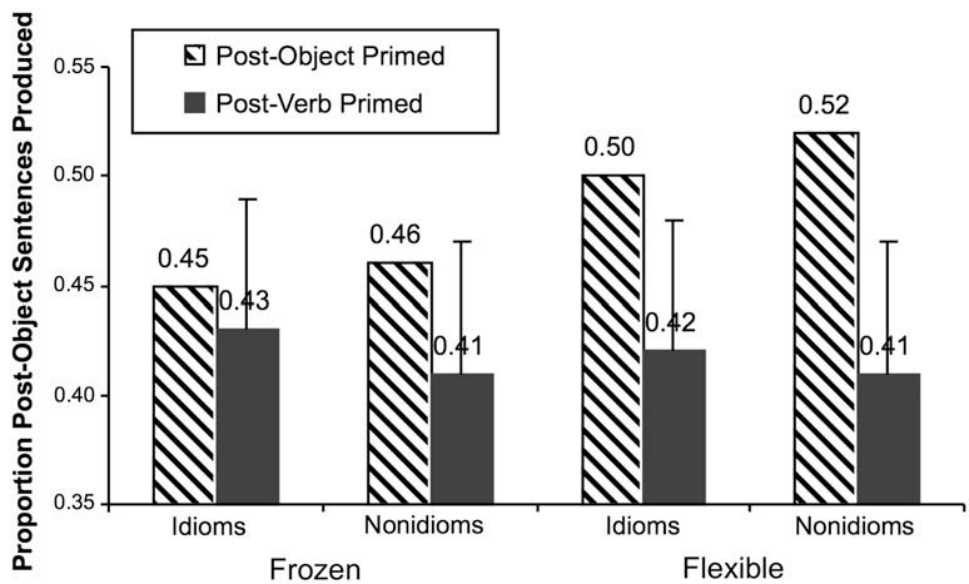

Fig. 3. Proportions of post-object sentences produced after frozen and flexible idiomatic and nonidiomatic primes in Experiment 2 (error bars represent the 95\% confidence interval for the difference between priming condition means). 
were somewhat more effective than frozen primes (with effects of .10 and .03 , respectively), yielding a marginally significant effect by participants only, $F_{1}(1,31)=3.74, p=.06, F_{2}(1,15)=1.35$. Most critically, idiomaticity did not deeply dent the effect of flexibility: The flexible-frozen differences in priming for idiomatic and nonidiomatic primes were both .06 and not significantly different, $F_{1}(1,31)=.01$, $F_{2}(1,15)=.04$.

To empirically validate the classification of items as syntactically frozen or syntactically flexible, we looked at the transformation patterns of the eight frozen primes and the eight flexible primes during prime reproduction. For the frozen primes, there were only six instances (out of 309 , or $2 \%$ ) when participants produced the prime in the alternative syntactic structure; for the flexible primes, there were 106 instances (out of 274 , or $39 \%$ ) when participants produced the prime with the alternative syntax. This difference confirms the categorization of the primes.

\subsection{Discussion}

Experiment 2 evaluated whether the generalizations stemming from structural priming are modulated by the idiomaticity or the syntactic flexibility of the priming sentences. Primes were drawn from the most strongly idiomatic and the most rigidly inflexible verb-particle constructions that we were able to identify. There were overall priming effects of the same magnitude as in Experiment 1. Idioms and nonidioms both yielded priming, with frozenness making the same contribution to priming in both cases. Structural flexibility overall elicited more priming than structural frozenness, and idiomaticity elicited somewhat less priming than nonidioms, but not significantly less. Flexibility and idiomaticity did not interact.

With respect to offering decisive evidence about the impact of idiomaticity on structural persistence, a limitation of this experiment was the small number of items that met the criteria for inclusion. The limitation allowed us to maximize the contrasts in idiomaticity and flexibility, with results suggesting that maximal idiomaticity did not do away with structural priming. More important, frozenness changed the magnitude of priming to the same extent for idiomatic and nonidiomatic expressions.

Although the reduction in priming for frozen idioms was completely aligned with the reduction for frozen nonidioms, Fig. 4 shows a priming effect for frozen idioms that is small enough to suggest an interestingly peculiar status for the most stereotypically idiomatic items. Unfortunately, there are practical obstacles to more sensitive evaluation of the combined contributions of idiomaticity and flexibility. We cannot easily increase the number of items (more inflexible, more idiomatic phrasal verbs being hard to find in English) or test more participants (many more than the 128 in the present experiment) in order to confirm the roles of idiomaticity and flexibility together or separately. This recommends a tighter focus on the factor that is most integral to lexicalist accounts of structural for-

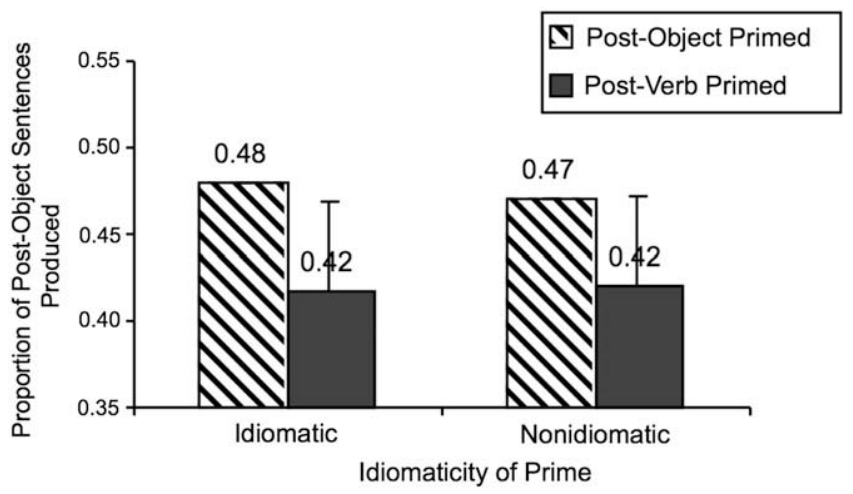

Fig. 4. Proportions of post-object sentences produced after idiomatic and nonidiomatic primes in Experiment 3 (error bars represent the $95 \%$ confidence interval for the difference between priming condition means). 
mulation and generalization. That factor is idiomaticity and its associated role in differentiating the lexical entries for words with different meanings, which are prominent in lexicalist accounts of structural storage (Jackendoff, 1997; Sprenger et al., 2006).

The results as they stand nonetheless suggest that flexibility is not critical in assessing the contribution of idiomaticity to structural persistence. So, in Experiment 3 we contrasted larger samples of flexible idiomatic and nonidiomatic primes to pin down the effect of idiomaticity on structural generalization.

\section{Experiment 3}

The purpose of Experiment 3 was to examine how idiomaticity affects structural persistence in a more powerful design. Priming from sentences with idiomatic phrasal verbs was compared to priming from sentences with nonidiomatic phrasal verbs to estimate the consequences of idiomaticity for syntactic generalization. If lexical accounts are correct, there should be clear differences in the priming patterns associated with idiomatic and nonidiomatic primes. If structural accounts are correct, idiomatic and nonidiomatic primes should not differ, replicating the results of Experiments 1 and 2.

To help to validate the involvement of known lexical processes in Experiment 3, we included a small set of prime-target pairs with repetitions of the full phrasal verb, the verb alone, and the particle alone. Because only the full phrasal verbs correspond to the presumed lexical entries for these items, we expected only full phrasal verb repetitions to elicit the lexical boost first observed by Pickering and Branigan (1998). The only existing account of the lexical boost attributes it to the shared subcategorizations of lexical entries.

\subsection{Method}

\subsubsection{Participants}

There were 96 undergraduates from the same source as Experiment 1, all native speakers of English. One bilingual speaker was replaced and eight other participants were replaced because they produced less than $50 \%$ codable responses to experimental items. The mean number of codable items per participant was $77.5 \%$, with a range from $46.9 \%$ to $100 \%$.

\subsubsection{Materials}

Thirty-two idiomatic and thirty-two nonidiomatic phrasal verbs were used (half of these verbs were also used in Experiment 1). One transitive sentence was written for each phrasal verb, and sentences were combined to obtain 32 experimental pairs such that equal numbers of the pairs, eight of each, consisted of idiomatic primes with idiomatic targets, idiomatic primes with nonidiomatic targets, nonidiomatic primes with idiomatic targets, and nonidiomatic primes with nonidiomatic targets. The four types of pairs are illustrated in Table 8. Finally, the prime and target in each pair were expressed with both post-verb and post-object particles for different participants, so each pair appeared in four different versions. Reversal of the prime and target sentences created four additional versions of the same pair, for a total of eight versions per pair. The complete set of pairs is shown in Appendix C, without the structural variations.

\section{Table 8}

Examples of prime and target types in Experiment 3

\begin{tabular}{ll}
\hline Prime and target types & Examples \\
\hline Idiomatic, post-verb & $\begin{array}{l}\text { The governor never lived down the shocking incident } \\
\text { The teenager shot off his mouth }\end{array}$ \\
Idiomatic, post-object & $\begin{array}{l}\text { The governor never lived the shocking incident down } \\
\text { The teenager shot his mouth off }\end{array}$ \\
Nonidiomatic, post-verb & $\begin{array}{l}\text { The graduating senior sent in his application } \\
\text { The apprentice boiled away all the lemon juice } \\
\text { Nonidiomatic, post-object }\end{array}$ \\
& $\begin{array}{l}\text { The graduating senior sent his application in } \\
\text { The apprentice boiled all the lemon juice } a w a y\end{array}$ \\
\end{tabular}


A parallel set of 32 pairs was created by recombining every prime with a target sentence from the opposite idiomaticity category of its original pairmate. So, if an idiomatic prime was paired with an idiomatic target in the first set of items, in the second set it was paired with a nonidiomatic target. Consequently, every target appeared both with an idiomatic and with a nonidiomatic prime.

The resulting 64 pairs completely crossed the factors of prime and target idiomaticity. In every cell of this factorial, 16 pairs were in turn divided into four other categories determined by the length of the direct objects and by particle repetition. Four pairs in every cell had long primes $(M=5.8)$ with short targets $(M=2.5)$, four had short primes $(M=2.3)$ paired with long targets $(M=5.9)$, and four had primes and targets of equal lengths $(M=3.8)$. The remaining four pairs in every cell had primes and targets of near-equivalent length $(M=3.6$ and 3.5 , respectively) with same-particle verbs. Across all the pairs, then, there were 16 in each of these four categories.

In addition to particle repetition, lexical repetition was manipulated in two other ways. First, within the 16 pairs that contained particle repetition, we varied verb overlap between the primes and targets. Four of the pairs had the same verbs, to create overlap in the entire phrasal verb (e.g., "The bartender picked up a girl" paired with "The janitor picked up the garbage"). In these pairs, one of the verbs was always idiomatic and the other nonidiomatic. (We kept the number of pairs with phrasal verb overlap small in order to minimize the chances of participants inferring relationships between successive sentences in the lists.) Second, across the 48 pairs in the three length-varying categories, there were 12 pairs in which the verb alone was repeated, four in each of the three length combinations. In total, there were 36 pairs with no lexical overlap, 12 pairs in which primes and targets shared verbs but not particles, 12 in which primes and targets shared particles but not verbs, and four in which primes and targets shared the complete phrasal verb.

The 32 original prime-target pairs were arranged in eight lists. Each list contained one of the eight versions of each pair and an equal number of pairs representing the combinations of prime and target form with prime and target idiomaticity. Across lists, each of the eight versions of every pairing occurred once. A second parallel set of eight lists contained the re-pairings of the primes and targets; these lists were otherwise identical in construction to the first set. The sequence of pairs in a list was subject to the same constraints as in Experiment 1. Lists were divided into eight blocks, which were rotated to distribute practice and fatigue effects.

Experimental trials were separated by seven filler sentences in all lists. The 226 fillers were similar to those used in Experiments 1 and 2. In total, each participant read and reconstructed 290 apparently unrelated sentences during an experimental session, one on each trial.

\subsubsection{Item norming}

Ratings were collected for all the experimental sentences on the judged idiomaticity of the verbs, as well as for acceptability of the post-verb and post-object versions of each sentence. None of the raters took part in the priming experiment.

For the idiomaticity judgments, 48 participants were asked to rate the idiomaticity of the phrasal verbs in the experimental sentences on a 7 -point scale ( $1=$ "not idiomatic", 7 = "highly idiomatic"). Idiomaticity was defined as in Experiment 2. Half of the participants rated sentences with particles in post-verb position, and half rated sentences with particles in post-object position. The results showed that the verbs in the idiomatic items were rated considerably higher on this scale than were the nonidiomatic verbs, 5.12 vs. $2.42, t(62)=13.02$ (see Table 9 ).

Ratings of acceptability were collected from 48 different participants. They were asked to rate how natural each of the 64 experimental sentences sounded to them on a 7 -point scale $(1=$ "not natural at

Table 9

Mean idiomaticity and acceptability ratings (with standard deviations) for materials in Experiment 3

\begin{tabular}{llll}
\hline Idiomaticity classification & Idiomaticity rating & \multicolumn{2}{l}{ Acceptability rating } \\
\cline { 3 - 4 } & & Post-verb particle & Post-object particle \\
\hline Idiom & $5.12(.92)$ & $5.10(.73)$ & $4.48(.58)$ \\
Nonidiom & $2.42(.73)$ & $5.35(.63)$ & $4.89(.64)$ \\
\hline
\end{tabular}


all", 7 = "very natural"). Each participant received an equal number of sentences in post-verb (16 idiomatic, 16 nonidiomatic) and post-object (16 idiomatic, 16 nonidiomatic) constructions, interspersed among 64 filler sentences. Overall, sentences with post-verb particles were judged to sound more natural than sentences with post-object particles, $5.22 \mathrm{vs.} 4.69$, and nonidiomatic sentences were rated as more natural than idiomatic, 5.12 vs. 4.79 . A 2 (post-verb vs. post-object particle) $\times 2$ (idiomatic vs. nonidiomatic) mixed analysis of variance performed on the acceptability ratings showed that both of these differences were statistically significant, $F(1,62)=50.89$ for the structural difference and $F(1,62)=5.13$ for the idiomaticity difference. The difference between post-verb and post-object structures was .62 for idioms and .45 for nonidioms; this interaction between idiomaticity and structure preference was not significant, $F(1,62)=1.17$.

\subsubsection{Procedure}

The procedure was identical to that described for Experiments 1 and 2. Each session took approximately $35 \mathrm{~min}$ to complete.

\subsubsection{Scoring}

Scoring criteria were identical to those used in the second experiment, and yielded a distribution of rejected trials that was comparable to those of the first two experiments (see Table 2). Responses were excluded on 275 trials (9.0\%) because the prime was reconstructed in the alternate structure. Again, the vast majority of these were cases of post-object primes being reconstructed with post-verb syntax (209 sentences out of 275 ). Another $12.1 \%$ of all responses (373 trials) were excluded because the prime was produced incorrectly and 9.7\% (297 trials) were excluded because the targets were produced incorrectly. Among the exclusions were 24 responses in which either the prime or the target sentence was incorrectly reconstructed with a verb of a different idiomatic status than was originally presented (e.g., the nonidiomatic "slept off an all-nighter" recalled as the idiomatic "pulled off an allnighter"). Analyses were performed on the remaining scorable $69.2 \%$ of all trials (2127 responses).

\subsubsection{Design and analyses}

There were 96 participants in each of 16 cells of the within-participant design formed by crossing the four factors of prime structure, target structure, prime idiomaticity, and target idiomaticity. A preliminary analysis was performed to assess general priming effects, pooling the data from the prime and target idiomaticity factors. Then, to minimize missing data in the primary analysis, the two levels of the target structure factor (which were counterbalanced for participants and items) were collapsed and the data were analyzed in the resulting 2 (prime structure) $\times 2$ (prime idiomaticity) $\times 2$ (target idiomaticity) design.

The design for items treated each of the 64 targets in their two structural forms as an item. There were 32 items representing each level of the between-items factor of target idiomaticity. This factor was completely crossed with the within-items factors of prime idiomaticity, prime structure, and target structure, and each of the 32 items in every cell of this design was presented to six participants. In the items analysis, the data were initially analyzed in the $2 \times 2 \times 2 \times 2$ design to assess target structure effects. Then, parallel to the participants analysis, data for the two target structures were pooled and a second $2 \times 2 \times 2$ analysis was performed.

Analyses of variance were performed as in Experiment 1, with degrees of freedom adjusted to reflect cells with missing data. The dependent variable in all analyses was the proportion of post-object forms produced out of all post-verb and post-object forms.

\subsection{Results}

\subsubsection{General priming effects}

The overall proportions and raw counts of post-verb and post-object forms produced in each priming and idiomaticity condition appear in Table 3, and the overall priming effect is shown in Fig. 2. Participants produced more post-object sentences following post-object primes (.47) than following post-verb primes (.42), yielding a significant effect of prime structure, $F_{1}(1,92)=4.21$, $F_{2}(1,63)=12.14, \operatorname{minF}^{\prime}(1,142)=3.13$. Participants tended to reuse the structure of the target sentences 
they had seen, producing .82 post-object constructions having read a post-object target and only .06 post-object constructions having read a post-verb target $\left(F_{1}(1,92)=740.15, F_{2}(1,63)=735.57\right.$, $\mathrm{min}$ $\left.F^{\prime}(1,149)=368.93\right)$. The interaction of these factors was not significant, $F_{1}(1,92)=.19, F_{2}(1,63)=$ 1.44. Because target structure is of little theoretical interest with respect to idiomaticity, below we report statistics only from the analyses that collapsed the target structure factor.

\subsubsection{Idiomaticity effects}

Fig. 4 plots the proportions of post-object sentences produced in the post-object and post-verb priming conditions after idiomatic and nonidiomatic primes, along with the $95 \%$ confidence interval for the differences between the conditions (calculated from the error term for the priming effect in the analysis including idiomaticity as a factor). Table 10 presents the numbers of responses in each condition. The difference between the post-object and post-verb conditions was similar for the two prime types: Idiomatic and nonidiomatic primes produced $5.9 \%$ and $5.3 \%$ increases in post-object sentence production, respectively. In the analysis of variance, the effect of the idiomaticity of the prime was not significant, $F_{1}(1,77)=.65, F_{2}(1,62)=.05$, and none of the interactions involving prime idiomaticity were significant, including the interactions between prime idiomaticity and prime structure, $F_{1}(1,77)=.11, F_{2}(1,62)<.01$, and between prime idiomaticity and target idiomaticity $F_{1}(1,77)=.20, F_{2}(1,62)=2.16$. Target idiomaticity was also not significant, $F_{1}(1,77)=.33$, $F_{2}(1,62)=.13$.

\subsubsection{Lexical repetition effects}

The subsets of items containing different degrees of lexical repetition were examined to see how repetition changed the priming effects. The data are broken down in Table 11, excluding 31 responses ( $1.5 \%$ of all scored responses) in which participants spontaneously introduced lexical overlap in items that lacked it or eliminated overlap in items that had it. This affected all items with incidental overlap in the particle alone, the verb alone, or the entire phrasal verb.

With no repetition, the priming effect (i.e., the difference between the post-object and post-verb priming conditions) was .06; with repetition of the particle alone the effect was .03 and with the main verb alone it was -.03 . The only sharp increase in priming relative to items with zero repetition occurred when the entire verb-particle construction was repeated, creating an overall priming effect of .18. Taking the idiomaticity of the primes into account, for the phrasal-verb-repeated items with idiomatic and nonidiomatic primes there were priming effects of .19 and .15, respectively. An unpaired $t$-test comparing priming for the items with full phrasal-verb repetition to priming for items with no repetition or only particle or verb repetition was significant, $t(126)=1.67, p<.05$, one-tailed.

\section{Table 10}

Proportions of post-object sentences produced (and total number of scored sentences) after idiomatic and nonidiomatic primes and targets in Experiment 3

\begin{tabular}{|c|c|c|c|}
\hline \multirow[t]{2}{*}{ Pairing and priming condition } & \multicolumn{2}{|c|}{ Presented target form } & \multirow[t]{2}{*}{ Overall } \\
\hline & Post-verb & Post-object & \\
\hline \multicolumn{4}{|l|}{ Idiomatic prime, idiomatic target } \\
\hline Post-object primed & $.06(125)$ & $.89(116)$ & .46 \\
\hline Post-verb primed & $.04(135)$ & $.83(140)$ & .44 \\
\hline \multicolumn{4}{|c|}{ Idiomatic prime, nonidiomatic target } \\
\hline Post-object primed & $.13(123)$ & $.84(126)$ & .49 \\
\hline Post-verb primed & $.03(146)$ & $.77(139)$ & .39 \\
\hline \multicolumn{4}{|c|}{ Nonidiomatic prime, idiomatic target } \\
\hline Post-object primed & $.07(123)$ & $.81(126)$ & .45 \\
\hline Post-verb primed & $.02(131)$ & .77 (149) & .42 \\
\hline \multicolumn{4}{|c|}{ Nonidiomatic prime, nonidiomatic target } \\
\hline Post-object primed & $.09(121)$ & $.87(132)$ & .50 \\
\hline Post-verb primed & $.01(143)$ & $.81(152)$ & .42 \\
\hline
\end{tabular}




\section{Table 11}

Proportions of post-object sentences produced (and total number of scored sentences) at different levels of lexical repetition in Experiment 3

\begin{tabular}{|c|c|c|c|}
\hline \multirow[t]{2}{*}{ Type of lexical repetition with priming condition (and form of item) } & \multicolumn{2}{|c|}{ Presented target form } & \multirow[t]{2}{*}{ Overall } \\
\hline & Post-verb & Post-object & \\
\hline \multicolumn{4}{|l|}{ No repetition } \\
\hline Post-object primed & $.11(268)$ & $.88(274)$ & .50 \\
\hline Post-verb primed & $.03(290)$ & $.84(296)$ & .44 \\
\hline \multicolumn{4}{|l|}{ Particle repetition } \\
\hline Post-object primed & $.04(91)$ & $.77(84)$ &. .39 \\
\hline Post-verb primed & $.01(124)$ & $.71(123)$ & .36 \\
\hline \multicolumn{4}{|l|}{ Verb repetition } \\
\hline Post-object primed & $.07(97)$ & $.87(95)$ & .47 \\
\hline Post-verb primed & $.03(94)$ & $.88(116)$ & .50 \\
\hline \multicolumn{4}{|l|}{ Verb-particle repetition } \\
\hline Post-object primed & $.03(29)$ & $.74(34)$ & .41 \\
\hline Post-verb primed & $.00(40)$ & $.46(41)$ & .23 \\
\hline
\end{tabular}

\subsubsection{Length effects in priming and production}

Table 4 summarizes the priming results from Experiments 1 and 3 in terms of how the lengths of the direct objects in the primes and targets were related, using the same exclusion criteria in both experiments.

In the present experiment, 1049 responses were included in the analysis. The differences between the post-object and post-verb priming conditions were .10 when the primes and targets were equal in length, .06 when the prime was short and the target long, and .01 when the prime was long and the target short. The half-width of the 95\% confidence interval for these differences, calculated from an analysis of variance on the items, was .04. Inspection of the data in the equal-length category indicated that the marginal priming effect for equal-length items was driven entirely by the four-syllable direct objects, which showed a priming effect of .19. For items with three-syllable direct objects the priming effect was -.11 , suggesting that there was no stable effect of length-matching.

As in Experiment 1, reproduction of the primes exhibited a consistent relationship between object heaviness and structure preference. For the 62 primes (out of 64) with transformed reproductions, participants reconstructed the primes to put particles after objects only when the direct objects were relatively short. So, for the post-verb-particle primes with the longest direct objects ( 7 syllables), 92\% of the transformations moved the particle from after the object to after the verb; in comparison, among the primes with the shortest direct objects ( 2 syllables), only $59 \%$ of the transformations moved the particle from post-object to post-verb position.

\subsection{Discussion}

Experiment 3 replicated the structural persistence pattern from the first two experiments in a direct comparison of idiomatic and nonidiomatic primes. The overall magnitude of structural persistence was the same as in Experiments 1 and 2, and did not differ when primes were idioms and when they were not. Thus, differences in the lexical-conceptual opacity of the verbs had no obvious impact on their effectiveness as primes. This implies that structural generalization occurs from primes to subsequent utterances despite variations in their lexical-conceptual semantics, in line with predictions from a structure-driven account of sentence building.

The experiment included an assessment of a lexical factor that powerfully affects structural priming, to validate the presence of a relevant type of lexical processing. Primes and targets sometimes had the same particles, verbs, or entire verb-particle constructions. There was pronounced enhancement of priming, a lexical boost, only in items with complete verb-particle overlap (e.g., Pickering \& Branigan, 1998). Since it is the complete verb-particle combination that constitutes the lexical entry for which lexical-conceptual and syntactic structures should be specified, this finding indicates that lexically specific processing occurred, with the expected large impact on structural priming. 


\section{General discussion}

The experiments reported here attempted to weigh the contributions of lexically driven and more abstract structural processes to production by assessing whether generalizations from the structures of idiomatic expressions were more restricted than generalizations from the structures of nonidiomatic expressions. Specifically, we compared the amount of structural persistence elicited by idiomatic and nonidiomatic phrasal verbs, examining how readily their structures generalized to new sentences. We used idioms because they are part of a class of expressions that have been seen as requiring the retrieval of lexically bound syntactic information (Sprenger et al., 2006). If the retrieval of specific lexically bound syntactic information has primacy over abstract structural processing, mechanisms responsible for productive combination would be expected to play a smaller role during the formulation of lexicalized expressions. However, if abstract structural formulation makes similar contributions to the production of idioms and nonidioms, it would argue for the generalized use of more abstract structure-building mechanisms during the formulation process. This is consistent with views in which structural processes unfold in parallel with, but separably from, lexical retrieval operations (Bock, 1990, 1995; Chang et al., 2006).

Experiment 1 showed that the position of a particle in phrasal verb constructions can be primed, in line with similar findings for that-complements (Ferreira, 2003), adjective phrases (Cleland \& Pickering, 2003), dative structures (Bock \& Griffin, 2000; Bock \& Loebell, 1990; Pickering \& Branigan, 1998), passives (Bock \& Griffin, 2000; Bock \& Loebell, 1990; Bock et al., 1992), and most closely related, auxiliary placement in Dutch (Hartsuiker \& Westenberg, 2000). A post-hoc analysis suggested that idiomatic and nonidiomatic phrasal verbs elicit structural persistence to a similar extent, and this hypothesis was more rigorously tested in Experiments 2 and 3.

Experiment 2 evaluated the contributions of idiomaticity and structural inflexibility to priming. Idiomaticity is stereotypically associated with structural inflexibility, and this inflexibility - frozenness - of idioms is commonly attributed to their lack of conceptual compositionality. Since literal expressions can be just as inflexible as idioms, the experiment compared the priming ability of flexible and frozen idioms to flexible and frozen nonidioms. The results showed that structural generalization occurred from both idioms and nonidioms, and was weakened by inflexibility to the same extent for both. This implies that structural inflexibility (which is known to reduce the impact of structural priming, most clearly in the guise of structural frequency; cf. Kaschak, Loney, \& Borregine, 2006) can, if controlled, be set aside in evaluating the contribution of idiomaticity to priming.

Experiment 3 addressed whether the specific lexical-syntactic structures hypothesized to be associated with idioms change the strength of structural persistence. The experiment used larger samples of idioms and nonidioms that were approximately equated for structural flexibility. The data showed near-identical levels of priming from idioms and nonidioms: The amount of structural generalization induced by the lexicalized structures, the idioms, was indistinguishable from the amount of structural generalization induced by structures that are, from a lexicalist standpoint, much more broadly shared across lexical entries. The implication is that, by this measure, any structures stored with idioms are not easily distinguished from any structures stored with nonidioms. Put differently, the structures that guide the production of idioms may be the same as the structures that guide the production of nonidioms, and may be more economically viewed as the products of mechanisms that generate abstractly specified structures for all utterances.

The similarities of idioms and nonidioms in ability to elicit structural generalization was accompanied by an informative result that helps to sharpen the conclusions. In Experiment 3, items in which phrasal verbs were repeated yielded a lexical boost, an effect that points to the workings of lexically specific processes within the experiment. The lexical boost that arises in structural priming has been attributed to the activation of the repeated verb's subcategorization by the prime, leading to the repeated use of the same structure in the target (Pickering \& Branigan, 1998). The presence of the boost makes it likely that the representations believed to be responsible for the syntactic privileges of idioms were at work in the experiments, but they did not modulate structural persistence.

A potential concern about the finding that idioms and nonidioms did not differ in priming ability is the possibility that participants may not have interpreted the idioms as idioms. Countering this con- 
cern was the tendency in Experiment 3 for participants' reconstruction of idiom targets to adhere to the preferred structure for the idiomatic sense more so than the reconstruction of nonidiomatic targets did. That is, the recall of idioms revealed that the normal structural preferences associated with idioms were present; recall of nonidiomatic verbs revealed different preferences. Consistent with the results of the norming study, speakers were sensitive to the idiomatic readings of the sentences with idiomatic verbs, and used the idioms as idioms.

Thus, except in respect to their priming efficacy, idioms behaved like idioms and nonidioms behaved like nonidioms. The disparity between the behavior of sentences in reproduction and their behavior as primes, in the same task and with the same kinds of processing on every trial, reinforces the claim that the syntax of both types of verbs was treated similarly when they served as primes. Expressions that were less susceptible to priming as targets were about equally likely to elicit priming when serving as primes, suggesting that the syntactic mechanisms involved in their production possess a degree of sensitivity to lexical biases that does not translate into restrictions on syntactic generalizability. These results do not challenge the existence of lexical correlations with structural biases. What they do challenge is the hypothesis that the syntactic mechanisms involved in sentence formulation are guided from a lexically specific representation of the structural biases.

This conclusion stems in part from considerations about alternative loci of structural priming effects. There is evidence that priming can influence syntactic processes (Bock \& Loebell, 1990), modulating a basic structural component of sentence formulation. There is also evidence that word order can be primed (Hartsuiker, Kolk, \& Huiskamp, 1999; Hartsuiker \& Westenberg, 2000). The word-order and structural accounts are not mutually exclusive, since different word-orders can appear in the same structure (e.g., on most analyses, a conjunction like salt and pepper has the same structure as pepper and salt), but other and maybe most cases of word-order alternation are mediated by structural variation. An important question about the changes we elicited in particle placement is whether there was structural variation behind the word-order variation.

The presence of a structural component in the present results gains credence from the highly variable composition of the phrases that occurred in prime-target pairings. If word order alone were at issue in the priming of particle placement, we would have expected variations in phrase structure and phrase length to interact consistently with priming. The object noun phrases in the prime and target sentences differed greatly in structure, ranging over determiner-noun sequences, determineradjective-noun sequences, noun phrases that contained another noun phrase and prepositional phrase, and so on. Priming occurred despite these variations. One reflection of this is that in the manipulations of phrase length in Experiments 1 and 3, different-length and same-length pairings co-varied with different and same structures, without systematically changing the priming effects. At an even finer grain, when the same sequences of form classes occurred in primes and targets in Experiments 1 and 3 (across a total of 80 items), the overall priming effect was .09. When different numbers and classes of words occurred as primes and targets, the overall effect was .05 (across a total of 126 items). Along with other work, this implies a structural contribution that may be enhanced by similarities in linear order, but is not reducible to linear order.

The results thus favor a view of syntactic processing that gives primacy to relatively abstract or generalized structural mechanisms in language production. This does not deny the force of lexically bound structural information in the use of individual words, since language production is obviously sensitive to lexically specific structural privileges for connecting words to one another (e.g., Levelt et al., 1999). The findings, however, tend to contest views that would make lexical specifications the initiating force, the dominant force, or the only force in the formulation of syntax, either for novel expressions or for overlearned expressions.

Why is this so? On strong lexicalist accounts of production, as we understand them, structures are built from the lexically bound structural information that becomes available upon word retrieval; on strong structural accounts, as we understand them, the primary source is more generalized structural information that organizes words within sentence frames. From lexicalist and constructionist perspectives, the process of structure-building is a by-product of lexical processing; from a structuralist perspective, word combination is a co-ordination problem directed by syntactic mechanisms and resolved by combining words on the fly in accordance both with general structural constraints and with specific lexical constraints. 
Of course, lexical-structural representation could be redundant. That is, it may be that words with the same structural privileges individually store the representations of those privileges. In adult language processing, such a situation would be difficult to distinguish from generalized or abstract structural constraints. However, there are two considerations that make redundant representation theoretically unattractive, in the absence of unequivocal evidence that redundant representation is needed to explain language performance. One is the widespread (though not necessarily correct) view that the lexicon stores information that is uniquely associated with specific lexical items, leaving structural processes to code what most verbs (for instance) have in common. Redundant representation runs against the considerations that associate peculiar, lexically specific information with individual lexical items (including the considerations that have made idioms a paradigm case for storing structure along with lexical information).

The second and more telling consideration lies in the developmental origins of syntax. The question of reliance on lexical retrieval compared to reliance on productive assembly in adult language processing finds its theoretical counterpart in debates about the acquisition of syntax in young children. On one influential view, individual words have been argued to function as idiomatic entities at early stages in development (Tomasello, 2000). Syntactic knowledge is anchored to individual lexical items before sufficient experience allows children to infer broader syntactic categories capable of supporting sentence-to-sentence structural generalization.

A central issue in this literature is how early a child's linguistic knowledge begins to show proof of abstractness. At odds with the strong lexicalist views are data suggesting that lexical items need not be the only source of syntactic knowledge. Preferential looking tasks, for example, show that children can use primitive syntactic representations to interpret events before they are able to use these structures in production (see Fisher, 2002a, 2002b, for review, and Chang et al., 2006, for a reconciliation of the early production and preferential looking results). This argues for early emerging syntactic competence and a more abstract understanding of syntactic relations than could result from knowledge of individual lexical entries alone. Drawing a parallel between these theories and theories of syntactic processing in mature speakers with fully formed grammars, the question is how syntax as a property of individual words relates to syntax as a process in its own right. The present experiments suggest that lexically bound structural information is not sufficient to explain the breadth of generalization of syntactic procedures over different utterances.

\subsection{Syntactic processing of idiomatic expressions}

Our findings extend prior results from the literature on idiom production and comprehension. At least two other studies suggest that idioms undergo the same syntactic analysis as literal expressions. Cutting and Bock (1997) elicited phrasal blends between idioms and nonidioms varying in syntactic or semantic similarity, and found that blending hinged on structural rather than meaning similarities, regardless of idiomaticity. Peterson et al. (2001) measured naming responses to words that completed idiomatic and nonidiomatic sentences, where the words varied in syntactic congruence. For example, after reading "The man was very old and feeble and it was believed he would soon kick the ..." or "The soccer player slipped when he tried to kick the. ..." participants named a visually presented noun (e.g., town) or a verb (e.g., grow). Response times to these words depended more on grammatical congruence than semantic congruence, and did so regardless of idiomaticity: Form class violations (i.e., producing the sentence-final verb grow when a noun was expected) slowed naming to the same extent for literal and idiomatic expressions. The effect was not modulated by the idioms' syntactic frozenness, reminiscent of the priming results in Experiment 2. The suggestion is that speakers and listeners are sensitive to the syntactic privileges of words, regardless of the lexical-semantic properties of the expressions in which they occur. In other words, expressions that are lexically noncompositional may nonetheless be syntactically compositional. The present data imply that the syntactic compositionality of idioms goes beyond the grammatical categorizations of individual words to encompass the structural properties of idiomatic phrases.

The findings also add to accumulating evidence for two different contributions to structural persistence, one from lexical processes and another from the structural processes involved in sentence formulation. Other work suggests that the specific lexical contribution is short-lived in comparison to the structural contribution (Hartsuiker, Bernolet, Schoonbaert, Speybroeck, \& Vanderelst, 2008; Konopka 
\& Bock, 2005), although the impact of lexical repetition is powerful. The lexical boost that we observed here was fairly large for idioms (.19) as well as nonidioms (.15), but it remains to be seen whether lexical repetition affects structural priming for idioms and nonidioms in the same ways. If the structural contributions to persistence are the same for idioms and nonidioms, it becomes important to assess whether and how the lexical contributions differ. Although the lexical representations of idioms may lack specific or dedicated structural information, the nature of the lexical representations that they do have may be illuminated with comparisons of different kinds and different amounts of lexical effects on structural priming. The lexical-conceptual representations of idioms proposed by Cutting and Bock (1997) and by Sprenger et al. (2006) suggest interesting differences in how lexical priming or repetition might affect the magnitude or the duration of structural persistence.

In other work on idiom representation, Kaschak and Saffran (2006) constructed artificial grammars that contained idiomatic and "core" (nonidiomatic) grammatical rules and examined learners' ability to learn the rules from the two types of constructions. The findings suggested that learning was impaired by idiomaticity, counter to our conclusion that structural generalizations from idioms and nonidioms are similar in strength. However, there is an important contrast with the present experiments. Kaschak and Saffran (2006) operationalized idiomaticity in terms of structural flexibility: Nonidiomatic constructions contained structural variations and idiomatic constructions did not. Our results from Experiment 2 showed that structural inflexibility does reduce structural persistence or generalization, but does so regardless of idiomaticity.

\subsection{Do properties of phrasal verbs affect priming?}

Some of the results of these experiments bear on issues that are specifically linked to questions about verb-particle constructions. Because these constructions have not been used previously in work on structural persistence, in this section, we summarize the major features of the results that are relevant to questions about construction-specific properties of phrasal verbs.

One question has to do with the role of metrical factors in structural priming. Because the positioning of particles in phrasal verbs is highly vulnerable to differences in the length or weight of direct objects (Arnold et al., 2000; Lohse et al., 2004), phrasal verbs offer a sensitive way to examine whether metrical similarity interacts with structural effects on priming. Experiments 1 and 3 explored this with subsets of items that paired primes and targets that matched or systematically differed in syllabic length. Experiment 1 showed no general effect of length-matching on priming, although there was a trend for post-object particle structures with long direct objects to elicit more priming. Experiment 3 revealed a stronger matched-length effect that was, however, entirely due to those items in which four-syllable direct objects preceded particles; three-syllable direct objects showed an opposing pattern. Though metrical priming may sometimes reinforce structural parallelism (Dooling, 1974; also see Szmrecsanyi, 2005), metrical properties on their own do not seem to promote structural variation (Bock \& Loebell, 1990, Experiment 3). This contention deserves continued scrutiny, but the results from Experiments 1 and 3 are consistent with it. The experiments showed at most an erratic relationship between length and priming variations for one of the most weight-sensitive constructions in English.

Our results for lexical repetition are informative about the nature of the lexical representations of phrasal verbs. The only type of repetition that effectively and substantially increased structural priming was repetition of the whole phrasal verb. This was not due to a summation of verb repetition and particle repetition, because these types of repetition on their own had little effect on structural persistence. In addition to confirming an important contribution of lexical factors to structural persistence (Cleland \& Pickering, 2003; Pickering \& Branigan, 1998), the findings strongly support the view that phrasal verbs are distinct lexical items and not composites of verbs and prepositions.

\subsection{Major limitations}

There are a good many limitations to these conclusions that must be kept in mind. We will mention here only two that seem especially pressing to us. First, given that our paradigm combines comprehension and production processes, an important question is whether the source of structural persistence is in language comprehension or language production. There is evidence that production and 
comprehension can both induce structural persistence (Branigan et al., 2000; Potter \& Lombardi, 1998) and that the strength and duration of persistence from these two sources may be the same (Bock, Dell, Chang, \& Onishi, 2007). The model of structural persistence proposed by Chang et al. (2006) actually locates the source of persistence in language comprehension.

Less clear is whether comprehension and production processes are equally susceptible to the impact of structural persistence, with some studies suggesting that they may differ in interesting ways. Unlike production processes, comprehension processes may not display effects of persistence in the absence of lexical overlap (cf. Branigan, Pickering, \& McLean, 2005), though emerging evidence indicates that structural persistence in comprehension can occur without lexical repetition (Thothathiri \& Snedeker, 2008a, 2008b). Because production of sentences was the measure of priming power in the present experiment, the most we can say about this issue is that regardless of whether priming occurred during target comprehension, sentence reproduction, or both, production was vulnerable to structural effects from idiomatic sentence primes.

A second limitation is the lack of an explicit account of how and when specific lexical-structural constraints and abstract structural constraints cooperate during sentence formulation. These experiments were not designed to pinpoint the locus of lexical effects, but only to assess their sufficiency for guiding structural processes in language production. The results suggest that a general type of abstract structural formulation occurs during sentence production that is not readily explained in terms of specific lexically represented structures. Nonetheless, there are lexical biases at work. When and how they come into play remains to be established.

\section{Conclusions}

The results of the present experiments suggest that sentence production calls on abstract structural formulation processes regardless of the strength of lexical-structural associations. We used phrasal verbs differing in idiomaticity and found effective generalization of structural configurations from sentence to sentence, irrespective of the nature of the lexical items present in the configuration initiating the generalization. So, even though syntactic information must be tied to lexical items (Levelt et al., 1999; Pickering \& Branigan, 1998) and is strongly associated with entire phrases in the case of idioms (Jackendoff, 1997; Sprenger et al., 2006), production does not seem to rely exclusively or even heavily on lexically specific syntactic connections. Instead, the evidence suggests that generalized sentence building procedures guide sentence formulation. If idioms call on generalized syntax, chances are that other types of expressions-whether literal or compositional in meaning, whether overlearned or completely novel-rely on generalized syntax, too.

\section{Appendix A. Experimental pairings used in Experiment 1, shown with post-verb particles only}

The angry drunk bashed in the windshield/Stress brought on his illness

The general carried out a successful operation/Mary looked over her son's homework All the actors put on their stage costumes/Eric stood up his date

The toddler threw away one of his broken toys/A hurricane blew in the windows The three suspects handed over their falsified passports/A revolt brought down the government Some police officers broke up the gathering/Neil explained away his blunders My dad's question touched off a heated discussion/A proctor handed out the exams The rich widow turned down all her suitors/The child finished off the cake Oil companies jacked up prices/All the trainees took in the new information Allison flipped over the pancakes/A model tried on the designer's latest dress Barbara dashed off a thank-you note/The bank analyst thought over the budget proposal The burglars broke down the door/The high prices scared off the poorer customers A maid let in the guests/All new players sat out the first two games The clique left out the newcomers/The scientist looked up the missing information Judy snapped on her earrings/The cook boiled away all the lemon juice 


\section{Appendix A (continued)}

Guards kept away the protesters/Few journalists wrote down the politician's answers Our tour guide pointed out the monument/The FBI tracked down the gang members Dr. Green wrapped up the conference/Brown's partner took over the company An architect added on the extra room/The gambler turned over seven more cards The board talked over the amendment/The programmer switched on his computer The librarian noted down out suggestions/The government beefed up law enforcement The bar raked in huge profits/Some sailors squared away the galley Some vacationers carried on large suitcases/The soccer team scaled down their ambitions The student slept off his all-nighter/The chief justice swears in the president His wife brings in a bigger paycheck/The noise woke up all the residents Some patients tried out the improved medicine/The hotel took in the stranded travelers Britney flicked on a cigarette lighter/Christie's auctioned away the entire collection Some companies laid off hundreds of workers/The bulldozer tore down the condemned building The agency brought up a funding issue/The drug dealers hid away some pure heroin My friends put off our trip to Boston/The shop owner sent away her two suppliers Loud music drowned out the conversation/The couple broke off their relationship The principal heard out the child's story/A cat knocked over the flower vase A celebrity threw in the first ball/All applicants turned in their best essays The editor picked out a glaring mistake/The economist worked out a financial strategy David's secretary passed on the memo/The bored driver turned on the radio Mayor Daly called off scheduled events/A large truck cut off the minivan Small details gave away the man's guilt/The flight attendant stowed away the tray A bomb blew up the power plant/The writer summed up his main points An injection calmed down the young woman/October's sales let down the store owner The beginner did over the complicated experiment/The speaker read over his presentation Smokers find it hard to give up their habit/Emily wasn't able to hold down a job All passengers have to fill in immigration forms/The Smiths had over some guests for dinner Lawyers sometimes try to lead on witnesses/Everyone needs to back up their computers The committee had to single out the best student/Squirrels lay in food for the winter The tourist forgot to map out the route/All candidates kick off their campaigns after Labor Day Many college graduates have to pay off loans/The blind man kept on his glasses at all times The family handed their title down through five generations/The miser wanted to bank away every penny

The administration passed over John for the promotion/An assistant filed away the documents yesterday

Both sentences in each pair occurred as primes and targets, with post-verb and post-object particles.

Appendix B. Experimental items used in Experiment 2

\begin{tabular}{|c|c|c|}
\hline Idiomaticity & Flexibility & Sentences \\
\hline \multicolumn{3}{|l|}{ Primes } \\
\hline \multirow[t]{8}{*}{ Idioms } & Frozen & Mary's grandpa finally gave up the ghost \\
\hline & & The New York mets brought up the rear \\
\hline & & Michael saw his relatives off at the airport \\
\hline & & The crooked salesman couldn't take the customer in \\
\hline & Flexible & The cop dug in his heels \\
\hline & & The teenager shot off his mouth \\
\hline & & The hikers broke their new boots in \\
\hline & & The hotel put some of the refugees up \\
\hline
\end{tabular}


Appendix B (continued)

\begin{tabular}{|c|c|c|}
\hline Idiomaticity & Flexibility & Sentences \\
\hline Nonidioms & Frozen & $\begin{array}{l}\text { Various gasses make up the atmosphere } \\
\text { The new material gave off a weird smell } \\
\text { The ambassador finally asked all the reporters in } \\
\text { The fugitives drove the old woman's car away } \\
\text { The cook flipped over the pancakes } \\
\text { Judy snapped on her earrings } \\
\text { The noise woke all the residents up } \\
\text { The graduating senior sent his application in }\end{array}$ \\
\hline \multicolumn{2}{|c|}{ Targets (all flexible nonidioms) } & $\begin{array}{l}\text { The cat knocked over the vase } \\
\text { The bored passenger turned on the radio } \\
\text { A model tried on the designer's latest dress } \\
\text { The secretary passed on the note } \\
\text { A celebrity threw in the first ball } \\
\text { The chief justice swears in the president } \\
\text { Some actors put on their stage costumes } \\
\text { The burglars broke down the front door } \\
\text { The skier brushed off the snow } \\
\text { Some patients tried out the medicine } \\
\text { Few journalists wrote down the politician's answers } \\
\text { The waitress finished off the cake } \\
\text { The jogger pulled off his sweatshirt } \\
\text { The toddler threw away one of his toys } \\
\text { The high prices scared off the customers } \\
\text { The janitor picked up the garbage }\end{array}$ \\
\hline
\end{tabular}

Prime sentences are shown in the structures used in the experiment; target sentences are shown with post-verb particles only, but also occurred in with post-object particles structures.

Appendix C. Experimental pairings used in Experiment 3 (shown in one pairing only and in postverb particle forms only); all sentences served as both primes and targets

Primes: idiomatic

Targets
(a) idiomatic
(b) nonidiomatic

The therapist brought up a touchy subject

(a) The mayor's speech brought down the house

(b) The storm blew in the windows

The governor never lived down the shocking incident

(a) The teenager shot off his mouth

(b) Judy snapped on her earrings

The shaken girl poured out her heart

(a) The noon traffic held up our guest of honor

(b) The toddler threw away one of his broken toys

Eric stood up his date

(a)The crime boss knocked off the sneaky informant

(b) A model tried on the designer's latest dress 
Appendix C (continued)

The tension wore down our excitement

(a) The triplets wore out their grandmother

(b) The chief justice swears in the president

The rich widow turned down all her suitors

(a) The gang members did in the drug dealer

(b) The bored driver turned on the radio

The comedian brushed off the insult

(a) The veteran showed off his medals

(b) The barber brushed off the boy's dandruff

The handyman ripped off the old lady

(a) The hooligans pulled off the robbery

(b) The child finished off the cake

Primes: idiomatic

Targets
(a) nonidiomatic
(b) idiomatic

The hired assassin took out the evil dictator

(a) The butcher sent away his helper

(b) The Yankees took on the Mets

Jeremy egged on his two younger brothers

(a) The cook flipped over the pancakes

(b) The cop dug in his heels

The soldier broke in his boots

(a) The burglars broke down the ancient wooden door

(b) A kitten stared down the German shepherd

A stranger put out the fire

(a) The apprentice boiled away all the lemon juice

(b) The rock band put off their concert in Chicago

The lawyer won over the jury

(a) The butler let in the neighbors

(b) The diver worked up his courage

The old boxer knocked out his opponent

(a) Several guards kept away the protesters

(b) The innkeeper put up the lost tourist

The professor backed up his student's story

(a) Lori backed up her minivan

(b) The police set up an innocent man

My roommate ran up the phone bill

(a) The noise woke up all the residents

(b) The bartender picked up a girl

Primes: nonidiomatic

Targets
(a) idiomatic
(b) nonidiomatic

The graduating senior sent in his application

(a) The Yankees took on the Mets

(b) The butcher sent away his helper

Few journalists wrote down the politician's answers

(a) The cop dug in his heels 
Appendix C (continued)

(b) The cook flipped over the pancakes

The drunk bashed in the windshield

(a) A kitten stared down the German shepherd

(b) The burglars broke down the ancient wooden door

The secretary passed on the note

(a) The rock band put off their concert in Chicago

(b) The apprentice boiled away all the lemon juice

All the actors put on their stage costumes

(a) The innkeeper put up the lost tourist

(b) Several guards kept away the protesters

The farmer let out the chickens

(a) The diver worked up his courage

(b) The butler let in the neighbors

The accountant summed up our expenses

(a) The police set up an innocent man

(b) Lori backed up her minivan

The janitor picked up the garbage

(a) The bartender picked up a girl

(b) The noise woke up all the residents

Primes: nonidiomatic

Targets

(a) nonidiomatic

(b) idiomatic

A small bomb blew up the local power plant

(a) The storm blew in the windows

(b) The mayor's speech brought down the house

Some patients tried out the new medicine

(a) Judy snapped on her earrings

(b) The teenager shot off his mouth

A celebrity threw in the first ball

(a) The toddler threw away one of his broken toys

(b) The noon traffic held up our guest of honor

A cat knocked over the vase

(a) A model tried on the designer's latest dress

(b) The crime boss knocked off the sneaky informant

The high prices scared off the customers.

(a) The chief justice swears in the president

(b) The triplets wore out their grandmother

The children hid away some cigarettes

(a) The bored driver turned on the radio

(b) The gang members did in the drug dealer

The student slept off his all-nighter

(a) The barber brushed off the boy's dandruff

(b) The veteran showed off his medals

The jogger pulled off his sweatshirt

(a) The child finished off the cake

(b) The hooligans pulled off the robbery 


\section{References}

Arnold, J. E., Wasow, T., Losongco, A., \& Ginstrom, R. (2000). Heaviness vs. newness: The effects of structural complexity and discourse status on constituent ordering. Language, 76, 28-55.

Bock, J. K. (1986). Syntactic persistence in language production. Cognitive Psychology, 18, 355-387.

Bock, J. K. (1987). Co-ordinating words and syntax in speech plans. In A. W. Ellis (Ed.), Progress in the psychology of language (pp. 337-390). London: Erlbaum.

Bock, J. K. (1989). Closed-class immanence in sentence production. Cognition, 31, 163-186.

Bock, J. K. (1990). Structure in language: Creating form in talk. American Psychologist, 45, 1221-1236.

Bock, J. K. (1995). Producing agreement. Current Directions in Psychological Science, 8, 56-61.

Bock, J. K., Dell, G. S., Chang, F., \& Onishi, K. (2007). Persistent structural priming from language comprehension to language production. Cognition, 104, 437-458.

Bock, J. K., \& Griffin, Z. M. (2000). The persistence of structural priming: Transient activation or implicit learning? Journal of Experiment Psychology: General, 129, 177-192.

Bock, J. K., \& Levelt, W. (1994). Language production: Grammatical encoding. In M. A. Gernsbacher (Ed.), Handbook of psycholinguistics (pp. 945-984). San Diego, CA: Academic Press.

Bock, J. K., \& Loebell, H. (1990). Framing sentences. Cognition, 35, 1-39.

Bock, J. K., Loebell, H., \& Morey, R. (1992). From conceptual roles to structural relations: Bridging the syntactic cleft. Psychological Review, 99, 150-171.

Branigan, H., Pickering, M., \& Cleland, A. (2000). Syntactic co-ordination in dialogue. Cognition, 75, B13-B25.

Branigan, H. P., Pickering, M. J., \& McLean, J. F. (2005). Priming prepositional-phrase attachment during comprehension. Journal of Experimental Psychology: Learning, Memory, and Cognition, 31, 468-481.

Britt, M. A. (1994). The interaction of referential ambiguity and argument structure in the parsing of prepositional phrases. Journal of Memory and Language, 33, 251-283.

Chang, F., Bock, K., \& Goldberg, A. E. (2003). Can thematic roles leave traces of their places? Cognition, 90, 29-49.

Chang, F., Dell, G. S., \& Bock, J. K. (2006). Becoming syntactic. Psychological Review, 113, 234-272.

Clark, H. H. (1973). The language-as-fixed-effect fallacy: A critique of language statistics in psychological research. Journal of Verbal Learning and Verbal Behavior, 12, 335-359.

Cleland, A. A., \& Pickering, M. J. (2003). The use of lexical and syntactic information in language production: Evidence from the priming of noun-phrase structure. Journal of Memory and Language, 49, 214-230.

Cohen, J. D., MacWhinney, B., Flatt, M., \& Provost, J. (1993). PsyScope: An interactive graphic system for designing and controlling experiments in the psychology laboratory using Macintosh computers. Behavior Research Methods, Instruments, E Computers, 25, 257-271.

Cutting, J. C., \& Bock, K. (1997). That's the way the cookie bounces: Syntactic and semantic components of experimentally elicited idiom blends. Memory \& Cognition, 25, 57-71.

Dooling, D. J. (1974). Rhythm and syntax in sentence perception. Journal of Verbal Learning and Verbal Behavior, 13, $255-264$.

Ferreira, V. S. (2003). The persistence of optional complementizer production: When saying "that" is not saying "that" at all. Journal of Memory and Language, 48, 379-398.

Fisher, C. (2002a). The role of abstract syntactic knowledge in language acquisition: A reply to Tomasello (2000). Cognition, 82, 259-278.

Fisher, C. (2002b). Structural limits on verb mapping: the role of abstract structure in 2.5-year-olds' interpretation of novel verbs. Developmental Science, 5, 55-64.

Frazier, L. (1987). Sentence processing: A tutorial review. In M. Coltheart (Ed.), Attention and performance XII: The psychology of reading (pp. 559-586). Hillsdale, NJ: Erlbaum.

Garnsey, S. M., Pearlmutter, N. J., Myers, E., \& Lotocky, M. A. (1997). The contributions of verb bias and plausibility to the comprehension of temporarily ambiguous sentences. Journal of Memory and Language, 37, 58-93.

Gibbs, R. W., \& Gonzales, G. P. (1985). Syntactic frozenness in processing and remembering idioms. Cognition, 20, 243-259.

Gibbs, R. W., Nayak, N. P., Bolton, J. L., \& Keppel, M. E. (1989). Speakers' assumptions about the lexical flexibility of idioms. Memory E Cognition, 17, 58-68.

Gibbs, R. W., Nayak, N. P., \& Cutting, J. (1989). How to kick the bucket and not decompose: Analizability and idiom processing. Journal of Memory and Language, 28, 576-593.

Goldberg, A. E. (1995). Constructions: A construction grammar approach to argument structure. Chicago: University of Chicago Press.

Gries, S. T. (2005). Syntactic priming: A corpus-based approach. Journal of Psycholinguistic Research, 34, 365-399.

Hartsuiker, R. J., Bernolet, S., Schoonbaert, S., Speybroeck, S., \& Vanderelst, D. (2008). Syntactic priming persists while the lexical boost decays: Evidence from written and spoken dialogue. Journal of Memory and Language, 58, 214-238.

Hartsuiker, R. J., Kolk, H. H. J., \& Huiskamp, P. (1999). Priming word order in sentence production. The Quarterly Journal of Experimental Psychology, 52A, 129-147.

Hartsuiker, R. J., Pickering, M. J., \& Veltkamp, E. (2004). Is syntax separate or shared between languages? Cross-linguistic syntactic priming in Spanish-English bilinguals. Psychological Science, 15, 409-414.

Hartsuiker, R. J., \& Westenberg, C. (2000). Word order priming in written and spoken sentence production. Cognition, 75 , B27-B39.

Jackendoff, R. (1997). Architecture of the language faculty. Cambridge, MA: MIT Press.

Jackendoff, R. (2002). Foundations of language: Brain, meaning, grammar, evolution. Oxford, New York: Oxford University Press.

Kaschak, M. P., Loney, R. A., \& Borregine, K. L. (2006). Recent experience affects the strength of structural priming. Cognition, 99, B73-B82.

Kaschak, M. P., \& Saffran, J. R. (2006). Idiomatic syntactic constructions and language learning. Cognitive Science, 30, 43-63.

Konopka, A. E., \& Bock, J. K. (2005). Helping syntax out: What do words do? Paper presented at the CUNY conference on human sentence processing, Tucson, Arizona. 
Kuiper, K. (1996). Smooth talkers: The linguistic performance of auctioneers and sportscasters. Mahwah, New Jersey: Lawrence Erlbaum Associates.

Levelt, W. J. M., Roelofs, A., \& Meyer, A. S. (1999). A theory of lexical access in speech production. Behavioral and Brain Sciences, 22, 1-75.

Loebell, H., \& Bock, J. K. (2003). Structural priming across languages. Linguistics, 41, 791-824.

Lohse, B., Hawkins, J. A., \& Wasow, T. (2004). Domain minimization in English verb-particle constructions. Language, 80, 238-261.

MacDonald, M. C., Pearlmutter, N. J., \& Seidenberg, M. S. (1994). Lexical nature of syntactic ambiguity resolution. Psychological Review, 101, 676-703.

Nunberg, G., Sag, I., \& Wasow, T. (1994). Idioms. Language, 70, 491-538.

Peterson, R. R., Burgess, C., Dell, G. S., \& Eberhard, K. M. (2001). Dissociation between syntactic and semantic processing during idiom comprehension. Journal of Experimental Psychology: Learning, Memory and Cognition, 27, 1223-1237.

Pickering, M. J., \& Branigan, H. P. (1998). The representation of verbs: Evidence from syntactic priming in language production. Journal of Memory and Language, 39, 633-651.

Pickering, M. J., Branigan, H. P., \& McClean, J. F. (2002). Constituent structure is formulated in one stage. Journal of Memory and Language, 46, 586-605.

Potter, M. C., \& Lombardi, L. (1990). Regeneration in the short-term recall of sentences. Journal of Memory and Language, 29, 633-654.

Potter, M. C., \& Lombardi, L. (1998). Syntactic priming in immediate recall of sentences. Journal of Memory and Language, 38, 265-282.

Quirk, R., Greenbaum, S., Leech, G., \& Svartvik, J. (1972). A grammar of contemporary English. London: Longman.

Ratcliff, R., Thapar, A., Gomez, P., \& McKoon, G. (2004). A diffusion model analysis of the effects of aging in the lexical-decision task. Psychology and Aging, 19, 278-289.

Snedeker, J., \& Trueswell, J. C. (2004). The developing constraints on parsing decisions: The role of lexical biases and referential scenes in child and adult sentence processing. Cognitive Psychology, 49, 238-299.

Sprenger, S. A., Levelt, W. J. M., \& Kempen, G. (2006). Lexical access during the production of idiomatic phrases. Journal of Memory and Language, 54, 161-184.

Szmrecsanyi, B. (2004). Persistence phenomena in the grammar of spoken English. Unpublished Ph.D. Dissertation, AlbertLudwigs-Universität Freiburg, Freiburg, Germany.

Szmrecsanyi, B. (2005). Creatures of habit: A corpus-linguistic analysis of persistence in spoken English. Corpus Linguistics and Linguistic Theory, 1, 113-149.

Thothathiri, M., \& Snedeker, J. (2008a). Syntactic priming during language comprehension in three- and four-year-old children. Journal of Memory and Language, 58, 188-213.

Thothathiri, M., \& Snedeker, J. (2008b). Give and take: Syntactic priming during spoken language comprehension. Cognition, 108, 51-68.

Tomasello, M. (2000). Do young children have adult syntactic competence? Cognition, 74, 209-253.

Wasow, T. (1977). Transformations and the lexicon. In P. W. Culicover, T. Wasow, \& A. Akmajian (Eds.), Formal syntax (pp. 327-360). New York: Academic Press.

Wood, M. G. (1986). Definition of idiom. Bloomington: University of Indiana Linguistics Club. 